\title{
Eastward-propagating planetary waves in the polar middle atmosphere
}

\author{
Liang Tang, Sheng-Yang Gu, and Xian-Kang Dou \\ Electronic Information School, Wuhan University, Wuhan, China \\ Correspondence: Sheng-Yang Gu (gushengyang@whu.edu.cn)
}

Received: 2 June 2021 - Discussion started: 17 June 2021

Revised: 5 November 2021 - Accepted: 5 November 2021 - Published: 1 December 2021

\begin{abstract}
According to Modern-Era Retrospective Research Analysis for Research and Applications (MERRA-2) temperature and wind datasets in 2019, this study presents the global variations in the eastward-propagating wavenumber 1 (E1), 2 (E2), 3 (E3) and 4 (E4) planetary waves (PWs) and their diagnostic results in the polar middle atmosphere. We clearly demonstrate the eastward wave modes exist during winter periods with westward background wind in both hemispheres. The maximum wave amplitudes in the Southern Hemisphere (SH) are slightly larger and lie lower than those in the Northern Hemisphere (NH). Moreover, the wave perturbations peak at lower latitudes with smaller amplitudes as the wavenumber increases. The period of the E1 mode varies between $3-5 \mathrm{~d}$ in both hemispheres, while the period of the E2 mode is slightly longer in the $\mathrm{NH}(\sim 48 \mathrm{~h})$ than in the $\mathrm{SH}(\sim 40 \mathrm{~h})$. The periods of the $\mathrm{E} 3$ are $\sim 30 \mathrm{~h}$ in both the $\mathrm{SH}$ and the $\mathrm{NH}$, and the period of E4 is $\sim 24 \mathrm{~h}$. Despite the shortening of wave periods with the increase in wavenumber, their mean phase speeds are relatively stable, $\sim 53, \sim 58$, $\sim 55$ and $\sim 52 \mathrm{~m} / \mathrm{s}$ at $70^{\circ}$ latitudes for E1, E2, E3 and E4, respectively. The eastward PWs occur earlier with increasing zonal wavenumber, which agrees well with the seasonal variations in the critical layers generated by the background wind. Our diagnostic analysis also indicates that the mean flow instability in the upper stratosphere and upper mesosphere might contribute to the amplification of the eastward PWs.
\end{abstract}

\section{Introduction}

The dominance of large-amplitude planetary waves in the stratosphere, mesosphere and lower-thermosphere regions and their interactions with zonal mean winds are the primary driving forces of atmospheric dynamics. In addition, sudden stratospheric warmings (SSWs) and quasi-biennial oscillation (QBO) events can dynamically couple the entire atmosphere from the lower atmosphere to the ionosphere (Li et al., 2020; Yamazaki et al., 2020; Yadav et al., 2019; Matthias and Ern, 2018; Stray et al., 2015). Westward-propagating planetary waves are one of the prominent features during austral and boreal summer. Westward quasi-2 d waves (Q2DWs) are the most obvious representative waves and one of the most investigated phenomena using planetary wave observations. Most previous studies have focused on the westwardpropagating Q2DWs, i.e., zonal wavenumbers of 2 (W2), 3 (W3) and 4 (W4) modes (Lainer et al., 2018; Gu et al., 2018b; Wang et al., 2017; Pancheva et al., 2016; Gu et al., 2016a, b; Lilienthal and Jacobi, 2015; Gu et al., 2013; Limpasuvan and Wu, 2009; Salby, 1981). However, limited studies have been conducted to understand the seasonal variations in the occurrence date, peak amplitude and wave period for the eastward Q2DWs (Gu et al., 2017; Lu et al., 2013; Alexander and Shepherd, 2010; Sandford et al., 2008; Palo et al., 2007; Merzlyakov and Pancheva, 2007; Manney and Randel, 1993; Venne and Stanford, 1979).

Typically, Q2DWs are maximal after the summer solstice in the middle latitudes. The largest wave amplitudes generally appear near the mesopause in January-February in the Southern Hemisphere (SH) and in July-August the Northern Hemisphere (NH) (Tunbridge et al., 2011). W3 and W4 Q2DWs reach amplitudes during austral and boreal summer in the mesosphere and lower thermosphere, respectively. The 
seasonal variation in westward Q2DW activity is obvious (Liu et al., 2019; Gu et al., 2018b; Rao et al., 2017). By observing the long-term Q2DWs in the $\mathrm{NH}$ and $\mathrm{SH}$, Tunbridge et al. (2011) reported that W3 is generally stronger than the other two modes in the $\mathrm{SH}$, reaching an amplitude of $\sim 12 \mathrm{~K}$, while $\mathrm{W} 4$ is stronger than $\mathrm{W} 3$ in the $\mathrm{NH}$, reaching $\sim 4 \mathrm{~K}$. Moreover, W4 generally lives longer than W3, and W4 can still be observed after the ending of W3. A previous study has demonstrated that the wave source, instability, critical layer and mean zonal wind are the primary reasons for the seasonal variation in Q2DWs (Liu et al., 2004). By studying the long-term satellite datasets in the $\mathrm{SH}, \mathrm{Gu}$ et al. (2019) have suggested that the strongest events of W2, W3 and W4 could be delayed by increasing the zonal wavenumber, and these events would be indistinguishable during SSWs. The wave periods of $\mathrm{W} 4, \mathrm{~W} 3$ and $\mathrm{W} 2$ vary at around $\sim 41-56$, $\sim 45-52$ and $\sim 45-48 \mathrm{~h}$, respectively. Furthermore, W2 can be observed using global satellite datasets, but it has an amplitude that is weaker than W3 and W4 in the NH and SH (Meek et al., 1996). The propagation and amplification of Q2DWs are primarily modulated by the instability, refractive index and critical layer, while the variation in background wind may cause different zonal wavenumber events (Gu et al., 2016a, b). By analyzing the variation in Q2DW activity during SSWs, Xiong et al. (2018) noticed that W1 (westward-propagating wave with wavenumber 1) is generated by the nonlinear interaction between SPW2 (stationary planetary wave with wave number 2) and W3. During SSWs, the coupling between the NH and SH can enhance the summer easterly and promote the nonlinear interaction between W3 and SPW1 (stationary planetary wave with wave number 1) (Gu et al., 2018b).

Some recent studies have discovered significant eastward planetary waves in the polar stratosphere and mesosphere regions, with periods of nearly 2 and $4 \mathrm{~d}$ (Gu et al., 2017; Sandford et al., 2008; Merzlyakov and Pancheva, 2007; Coy et al., 2003; Manney and Randel, 1993). Planetary waves with zonal wavenumbers -1 (E1) and -2 (E2) correspond to 4 and $2 \mathrm{~d}$ waves, respectively. Furthermore, planetary waves of $1.2 \mathrm{~d}$ with wavenumber -3 (E3) and $0.8 \mathrm{~d}$ with wavenumber -4 (E4) have been reported to contain the same phase speeds as E1 and E2 (Manney and Randel, 1993). This series of eastward planetary wave can significantly affect the thermal and dynamic structure of the polar stratosphere, resulting in profound changes in its wind and temperature (Coy et al., 2003; Venne and Stanford, 1979). Beyond the knowledge about nonlinear interactions between migrating tides and Q2DWs (Palo et al., 1999), further investigation has confirmed that E2 Q2DW could be generated by the nonlinear interaction between planetary wave and tides in the mesosphere and lower thermosphere (MLT) (Palo et al., 2007). We should note that the E2 Q2DW generated in the MLT region is different from that in the polar stratosphere and is discussed in this paper.

By studying and analyzing satellite datasets, Merzlyakov and Pancheva (2007) indicated that the wave periods of
E1 and E2 events range between $1.5-5 \mathrm{~d}$. They reported that Eliassen-Palm (EP) flux travels from the upper to the lower atmosphere, meaning that the upper atmosphere has a dynamic influence on the lower atmosphere. Sandford et al. (2008) reported on significant fluctuations in E2 Q2DWs in the polar mesosphere. They indicated the influence of changes in mean zonal winds during a major SSW on the propagation of polar E2. In addition, they proposed the significance of E2 fluctuation in the mesosphere driven by the instabilities in the polar night jet. For E2, the amplitude of temperature, zonal wind and meridional wind during the austral winter can reach $\sim 10 \mathrm{~K}, \sim 20 \mathrm{~m} / \mathrm{s}$ and $\sim 30 \mathrm{~m} / \mathrm{s}$, respectively, while those during the boreal winter can drop by almost two-thirds. Lu et al. (2013) found that eastward planetary wave propagation is limited to the winter high latitudes probably because the negative refractive indices equatorward of $\sim 45^{\circ} \mathrm{S}$ result in evanescent wave characteristics. That study suggested that the instability region at $\sim 50-60^{\circ} \mathrm{S}$ might be induced by the stratospheric polar night jet and/or the "double-jet" structure.

In this study, we use the second Modern-Era Retrospective Research Analysis for Research and Applications (MERRA2) datasets to investigate the eastward-propagating wave characteristics of the stratosphere and mesosphere in polar regions in 2019, including E1, E2, E3 and E4. Specifically, we investigate the variation in the occurrence date, peak amplitude and wave period of eastward waves, as well as the role of instability, background wind structure and the critical layer in the propagation and amplification of eastward waves. The remaining parts of this paper are organized as follows. Section 2 describes the data and methods used in this study. Section 3 analyzes the global latitude-temporal variation structure of eastward waves during winter in 2019. The amplification and propagation features of the eastward planetary waves in the $\mathrm{NH}$ and $\mathrm{SH}$ with different wavenumber events are examined in Sect. 3.1 and 3.2, respectively. Section 3.3 compares and analyzes the eastward waves in the $\mathrm{NH}$ and SH. All research results are summarized in Sect. 4.

\section{Data and analysis}

To extract the E1, E2, E3 and E4 wave, we apply the leastsquares method to each time window (i.e., 10, 6, 4 and $4 \mathrm{~d}$ ), and then use the time window to determine the amplitude $(\mathrm{Gu}$ et al., 2013). This method has been shown to successfully identify planetary waves from satellite measurements (Gu et al., 2019, 2018a, b, c, 2013).

$y=A \cos [2 \pi(\sigma \cdot t+s \cdot \lambda)]+B \sin [2 \pi(\sigma \cdot t+s \cdot \lambda)]+C$

The least-squares method is used to fit the a set of parameters ( $A, B$ and $C$ ), where $\sigma, t, s$ and $\lambda$ are the frequency, UT time, zonal wavenumber and longitudes. The amplitude of wave $R$ can be expressed as $R=\sqrt{A^{2}+B^{2}}$. 
MERRA-2 covers the long-term atmospheric reanalysis datasets initiated by NASA in 1980. It has been upgraded recently using the Goddard Earth Observing System model, Version 5 (GEOS-5) data assimilation system. Briefly, MERRA-2 includes some updates to the model (Molod et al., 2015, 2012) and the global statistical interpolation (GSI) analysis scheme of $\mathrm{Wu}$ et al. (2002). The MERRA-2 data consist of various meteorological variables, e.g., net radiation, temperature, relative humidity and wind speed. The spatial coverage of MERRA-2 data is the globe (spatial resolution, $0.5^{\circ} \times 0.625^{\circ}$; temporal resolution, $1 \mathrm{~h}$ ). These meteorological data are widely used to detect the middle atmosphere such as the planetary wave in the polar atmosphere, global thermal tides, climate variability and aerosol (Ukhov et al., 2020; Sun et al., 2020; Bali et al., 2019; Lu et al., 2013). Many recent studies have indicated the feasibility of using MERRA-2 data for the kind of research in the present study. Therefore, we apply the MERRA-2 datasets to obtain the variation in the background wind, instability, refractive index and critical layer; and we explore the patterns of eastward planetary wave propagation and amplification through diagnostic analysis.

The critical layer will absorb or reflect planetary waves from the lower atmosphere during upward propagation. Planetary waves that gain sufficient energy in the unstable region will be amplified during reflection. In a sense, the critical layer plays an important role in regulating the amplification and propagation of planetary waves (Gu et al., 2016a, b; Liu et al., 2004).

$\overline{q_{\varphi}}=2 \Omega \cos \varphi-\left(\frac{(\bar{u} \cos \varphi)_{\varphi}}{a \cos \varphi}\right)_{\varphi}-\frac{a}{\rho}\left(\frac{f^{2}}{N^{2}} \rho \overline{u_{z}}\right)_{z}$

The baroclinic and/or barotropic instability in the atmospheric space structure is caused by the simultaneous equalization of the negative latitude gradient and the quasigeostrophic potential vorticity $\left(\overline{q_{\varphi}}\right)$. In Eq. (2), $\Omega$ is the angular speed of the Earth's rotation, $\varphi$ is the latitude, $\bar{u}$ is the zonal mean zonal wind, $a$ is the Earth's radius, $\rho$ is the air density, $f$ is the Coriolis parameter, $N$ is the buoyancy frequency, and subscripts $z$ and $\varphi$ are the vertical and latitudinal gradients.

According to Andrews et al. (1987), the properties of planetary wave propagation can be calculated using the EP flux vectors $(F)$; i.e.,

$F=\rho a \cos \varphi\left[\begin{array}{l}\frac{\overline{u_{z}} \overline{v^{\prime} \theta^{\prime}}}{\overline{\theta_{z}}}-\overline{v^{\prime} u^{\prime}} \\ {\left[f-\frac{(\bar{u} \cos \varphi)_{\varphi}}{a \cos \varphi}\right] \frac{\overline{v^{\prime} \theta^{\prime}}}{\overline{\theta_{z}}}-\overline{w^{\prime} u^{\prime}}}\end{array}\right]$,

where $u^{\prime}$ and $v^{\prime}$ are the planetary wave perturbations in the zonal and meridional wind, respectively, and $\theta^{\prime}$ and $w^{\prime}$ are the potential temperature and vertical wind, respectively. The planetary wave propagation is only favorable where the square of the refractive index $m^{2}$ is positive:

$m^{2}=\frac{\overline{q_{\varphi}}}{a(\bar{u}-c)}-\frac{s^{2}}{(a \cos \varphi)^{2}}-\frac{f^{2}}{4 N^{2} H^{2}}$,

where $s$ is the zonal wavenumber, $c$ is the phase speed and $H$ is the scale height. The square of the refractive index is taken as the waveguide of planetary waves; i.e.,

$c=-v_{0} \cos \left(\frac{\varphi \pi}{180}\right) / s T$,

where $v_{0}$ is the equatorial linear velocity, $s$ is the zonal wavenumber and $T$ is the wave period.

\section{Results and discussion}

We considered the entire period of 2013-2020 and found that the temporal variations in the eastward planetary waves during 2019 are representative of all years in this range. We thus will only present the results for the year 2019. Figure 1 shows the global temporal-latitude variation structures of E1, E2, E3 and E4 extracted from the 2019 MERRA-2 temperature datasets using time windows of 10, 6, 4 and $4 \mathrm{~d}$, respectively. The mean temperature amplitude of E1, E2, E3 and E4 at $\sim 55.4 \mathrm{~km}$ during the periods $3-5,1.5-2.5,1-1.5$ and $0.9-$ $1.1 \mathrm{~d}$ are displayed in Fig. 1a, b, c and d, respectively. Eastward waves are characterized by obvious seasonal variations in the SH and NH. In addition, E1, E2 (E3) and E4 reach their maximum amplitude at $50-80^{\circ}(\mathrm{S}$ and $\mathrm{N}$ ). In the $\mathrm{SH}$, the strongest E1 and E2 events occur on days 209-218 and 167-172, while E3 and E4 events occur on days 151-154 and 139-142. This means that their occurrence date of maximum amplitude moves earlier with increasing zonal wavenumber. In addition, the maximum amplitude of E1, E2, E3 and E4 are $\sim 6.0, \sim 4.2, \sim 3.6$ and $\sim 2.4 \mathrm{~K}$, respectively, indicating that their peak amplitudes drop with rising zonal wavenumber. In the $\mathrm{NH}$, the strongest E1, E2, E3 and E4 events occur on days 41-50, 69-74, 35-38 and 63-66, respectively; the corresponding peak amplitudes are $\sim 5.5, \sim 3.8, \sim 2.8$ and $\sim 1.2 \mathrm{~K}$, respectively. While the results demonstrate the decline in the peak amplitude with increasing zonal wavenumber in the $\mathrm{NH}$, the occurrence date is irregular. Moreover, E4 is relatively weak in the $\mathrm{NH}$ and difficult to find, so W4 is insignificant in the NH. Figure 2 presents the changes in zonal mean zonal wind at $70^{\circ} \mathrm{S}$ and $70^{\circ} \mathrm{N}$ in 2019 . It can be seen that the background wind on days $90-240\left(70^{\circ} \mathrm{S}\right)$ is dominated by westward wind and reaches $\sim 80 \mathrm{~m} / \mathrm{s}$ at $\sim 50 \mathrm{~km}$ on day 210; it is dominated by eastward wind in late and early 2019 and reaches approximately $-40 \mathrm{~m} / \mathrm{s}$ at $\sim 60 \mathrm{~km}$. Meanwhile, the background wind is primarily westerly in late and early $2019\left(70^{\circ} \mathrm{N}\right)$ and reaches $\sim 90 \mathrm{~m} / \mathrm{s}$ at $\sim 60 \mathrm{~km}$ on day 50, while on days 120-240, the background wind is primarily easterly wind, and the amplitude reaches $-40 \mathrm{~m} / \mathrm{s}$ on day 200. Compared with Fig. 1, the results show that the eastward wave modes exist during winter periods with westward background wind in both hemispheres. 


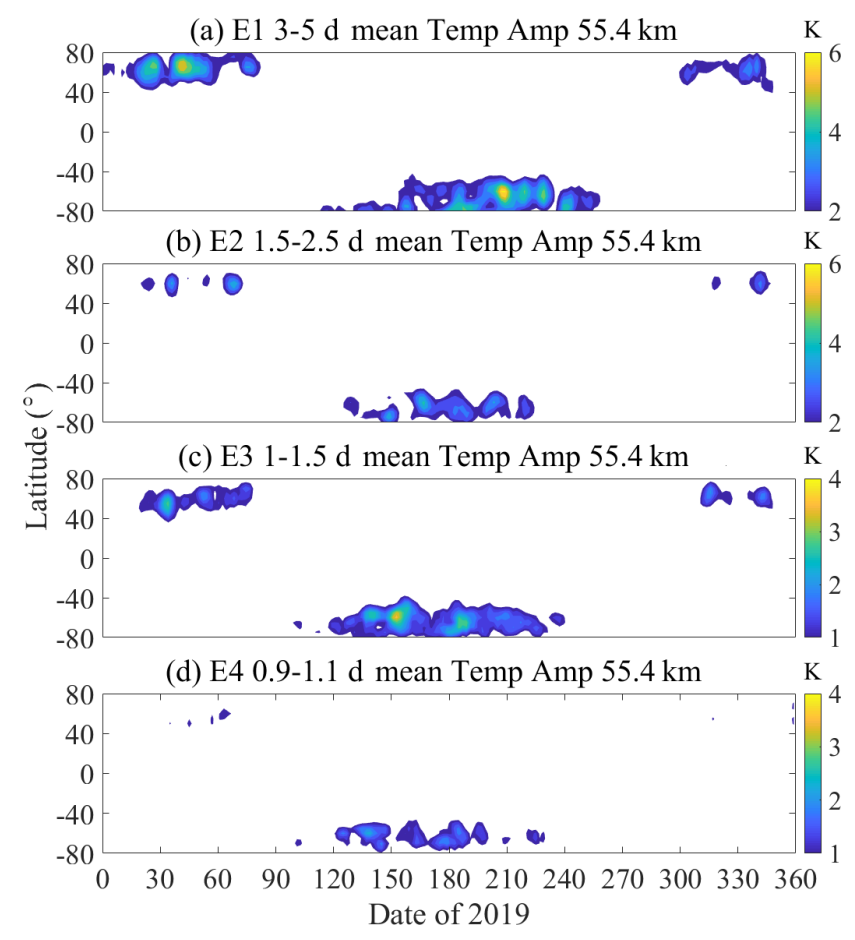

Figure 1. The global latitude-temporal variation structures of the (a) E1, (b) E2, (c) E3 and (d) E4 planetary waves during 2019. White areas represent small-amplitude data (corresponds to the right color bar). The date indicates the day of the year.

\subsection{In the Southern Hemisphere}

Figure 3 shows that the observed maximum temperature amplitude is at $\sim 48.2 \mathrm{~km}$ and $\sim 70-80^{\circ} \mathrm{S}$ for $\mathrm{E} 1, \sim 48.2 \mathrm{~km}$ and $\sim 60-70^{\circ} \mathrm{S}$ for $\mathrm{E} 2$ and $\mathrm{E} 3$, and $\sim 48.2 \mathrm{~km}$ and $\sim 50$ $60^{\circ} \mathrm{S}$ for E4. For E1, the observed maximum perturbation occurs on days $211-220$ (with an amplitude of $\sim 8.5 \mathrm{~K}$ ), and the remaining fluctuations occur on days 161-170, 187-196 and 231-240. For E2, the observed maximum perturbation happens at days 219-224 (with an amplitude of $\sim 7.8 \mathrm{~K}$ ), and three peaks appear on days 139-144, 173-178 and 187192. Regarding E3, the strongest perturbation occurs on days 151-154 (with an amplitude of $\sim 5.2 \mathrm{~K}$ ) and the other events are distributed on days 141-144, 201-204 and 209-202. E4 perturbations are distributed on days 127-130, 145-148, 161-164 and 213-216, with a weak amplitude of $\sim 3 \mathrm{~K}$. Since earlier studies mentioned that the wave period of the eastward wave can vary, we also investigate the periodic variabilities in E1, E2, E3 and E4. The results show that the period corresponding to the maximum perturbation of E1 falls between $\sim 106$ (days 187-196) and $\sim 69$ h (days 211-220), and their wave periods vary significantly. Nonetheless, the wave period of E2 gradually changes from $\sim 42$ (days 139144) to $\sim 38 \mathrm{~h}$ (days $219-224$ ), and its stability is stronger than that of E1. The wave periods of E3 and E4 are about $\sim 39$ and $\sim 24 \mathrm{~h}$, respectively. These results reflect that the E2, E3 and E4 wave periods are more stable compared to E1.

The spectra, spatial (vertical and latitudinal) structures of temperature, zonal and meridional wind, and diagnostic analysis of E1 are extracted from the two corresponding events (refer to Fig. 4). Figure 4a and b show the least-squares fitting spectra for MERRA-2 temperature on days 187-196 and $211-220$ at $\sim 48.2 \mathrm{~km}$ and $\sim 70-80^{\circ} \mathrm{S}$, when and where the E1 is maximal. An eastward wavenumber -1 signal with the periods of $\sim 106$ and $\sim 69 \mathrm{~h}$ clearly dominates the whole spectrum. The temperature spatial structures corresponding to these E1 periods (i.e., $\sim 106$ and $\sim 69 \mathrm{~h}$ ) are displayed in Fig. $4 c$ and d. The temperature spatial structure of E1 exhibits obvious amplitude bimodal structure at $\sim 70-80^{\circ} \mathrm{S}$ and $\sim 50 \mathrm{~km}$ and $\sim 70-80^{\circ} \mathrm{S}$ and $\sim 60 \mathrm{~km}$, with the maximum at $\sim 70-80^{\circ} \mathrm{S}$ and $\sim 50 \mathrm{~km}$. The strongest temperature amplitude of E1 occurs at $\sim 50 \mathrm{~km}$ and $\sim 70-80^{\circ} \mathrm{S}$ with an amplitude of $\sim 10 \mathrm{~K}$ on days $211-220$, and the other peak is $\sim 9 \mathrm{~K}\left(\sim 70-80^{\circ} \mathrm{S}\right.$ and $\left.\sim 60 \mathrm{~km}\right)$. The temperature amplitude of $\sim 9 \mathrm{~K}$ occurs at $\sim 50 \mathrm{~km}$ and $\sim 70-80^{\circ} \mathrm{S}$ during days $187-$ 196 , and the other events have a temperature amplitude of $\sim 7 \mathrm{~K}\left(\sim 70-80^{\circ} \mathrm{S}\right.$ and $\left.\sim 60 \mathrm{~km}\right)$. The corresponding spatial structures of zonal wind and meridional wind of these E1 events are shown in Fig. 4e-h. The maximum zonal wind amplitude of E1 occurs at $\sim 60-70^{\circ} \mathrm{S}$ and $\sim 60 \mathrm{~km}$ with an amplitude of $\sim 14 \mathrm{~m} / \mathrm{s}$ on days $187-196$ and $\sim 20 \mathrm{~m} / \mathrm{s}$ at $\sim 50$ $60^{\circ} \mathrm{S}$ and $\sim 60 \mathrm{~km}$ on days 211-220. The amplitude of E1 meridional wind hits $\sim 10 \mathrm{~m} / \mathrm{s}$ at $\sim 70-80^{\circ} \mathrm{S}$ and $\sim 55 \mathrm{~km}$ (days 187-196) and $\sim 17 \mathrm{~m} / \mathrm{s}$ at $\sim 70-80^{\circ} \mathrm{S}$ and $\sim 60 \mathrm{~km}$ (days 211-220).

Figure $4 \mathrm{i}$ and $\mathrm{j}$ show the diagnostic analysis results for the E1 events during days 187-196 and 211-220, respectively. Apparently, the EP flux vectors are more favorable to propagation in the SH winter and are dramatically amplified by the mean flow instabilities and appropriate background winds in the polar region and between $\sim 40$ and $\sim 80 \mathrm{~km}$, with EP flux propagating into the upper atmosphere (Fig. 4i). Meanwhile, there is an EP flux at the mid-latitudes and $\sim 60-80 \mathrm{~km}$, which propagates into the lower atmosphere. The wave-mean flow interaction near its critical layer (106h) of the green curve amplifies E1, and the positiverefractive-index region surrounded by the yellow curve also enhances E1 propagation. In addition, the strong instability and weak background wind at $\sim 70-80^{\circ} \mathrm{S}$ and $\sim 40-60 \mathrm{~km}$ provide sufficient energy for the upward EP flux to propagate and amplify. Nevertheless, the downward-propagating EP flux is amplified by weak instability and strong background wind at $\sim 50-60^{\circ} \mathrm{S}$ and $\sim 60-70 \mathrm{~km}$. Besides, both upward and downward EP fluxes eventually propagate toward the Equator at $\sim 50 \mathrm{~km}$. Figure $4 \mathrm{j}$ shows that EP flux on days 211-220 propagates downward and amplifies after the interaction of the critical layer $(\sim 69 \mathrm{~h})$. The positiverefractive-index region, strong instability and weak background wind at $\sim 50-60^{\circ} \mathrm{S}$ and $\sim 60-70 \mathrm{~km}$ provide sufficient energy for E1 amplification and propagation and ul- 
(a) 2019 Zonal Mean Zonal Wind at $70^{\circ} \mathrm{S}$
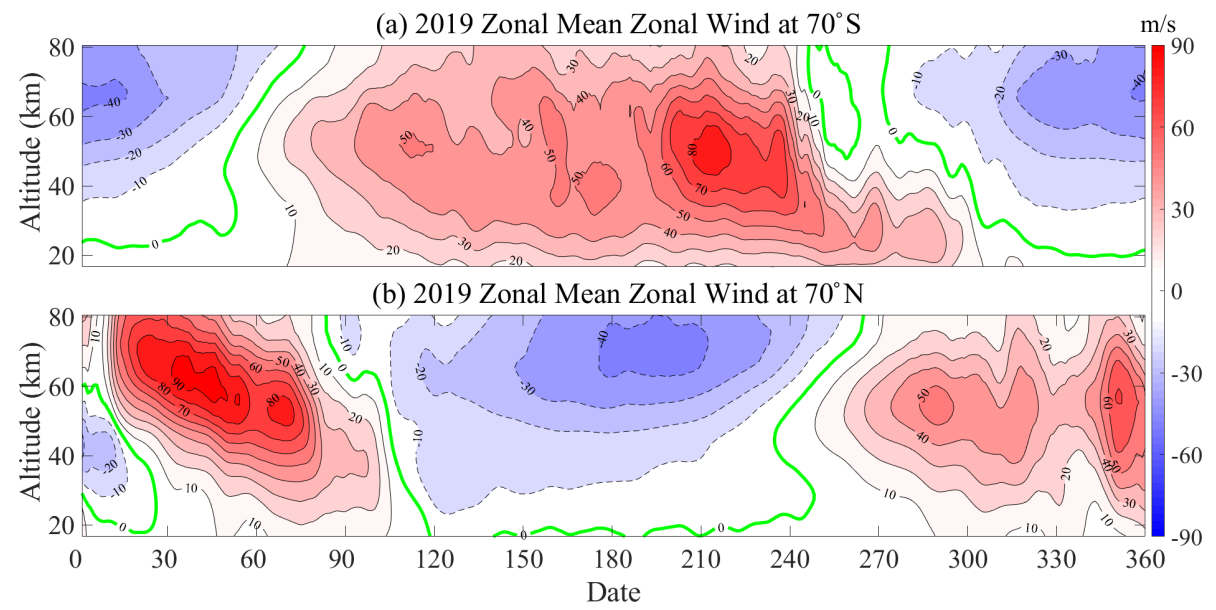

Figure 2. The zonal mean zonal wind variations of (a) $70^{\circ} \mathrm{S}$ and (b) $70^{\circ} \mathrm{N}$ during 2019 . The dashed lines represent eastward wind; the solid black lines represent westward wind; and the solid green line is $0 \mathrm{~m} / \mathrm{s}$. The date indicates the day of the year.

(a) Temperature E1 amplitude at $70-80^{\circ} \mathrm{S}$ and $48.2 \mathrm{~km} \mathrm{~K}$

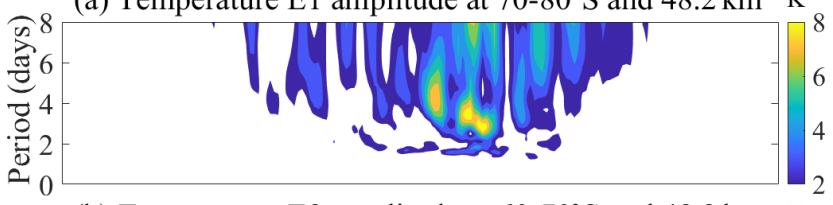

(b) Temperature E2 amplitude at $60-70^{\circ} \mathrm{S}$ and $48.2 \mathrm{~km} \mathrm{~K}$

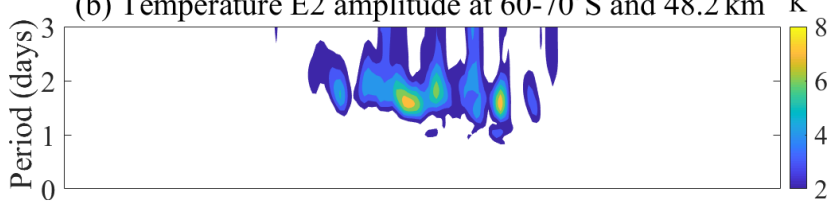

(c) Temperature E3 amplitude at $60-70^{\circ} \mathrm{S}$ and $48.2 \mathrm{~km} \mathrm{~K}$

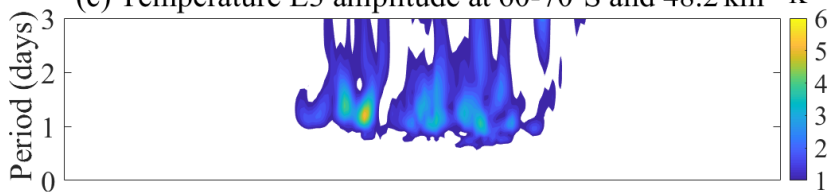

(d) Temperature E4 amplitude at $50-60^{\circ} \mathrm{S}$ and $48.2 \mathrm{~km} \mathrm{~K}$

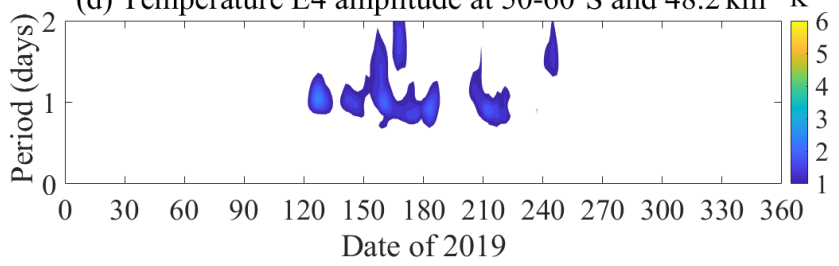

Figure 3. The temporal variations in (a) E1, (b) E2, (c) E3 and (d) E4 during the 2019 austral winter period. The date indicates the day of the year.

timately point toward the Equator at $\sim 50 \mathrm{~km}$. The results show that the weak background wind and strong instability in the polar region can promote the upward propagation and amplification of EP flux. Meanwhile, the appropriate background wind and instability in the mid-latitudes are also conducive to the downward propagation and amplification of EP flux. In other words, instability and appropriate background wind dominate the propagation and amplification of E1.
For E2, the spectra are observed at $\sim 48.2 \mathrm{~km}$ and $\sim 60$ $70^{\circ} \mathrm{S}$ on days $173-178$ and $219-224$ when the eastward wavenumber -2 becomes the primary wave mode with the wave periods $\sim 38$ and $\sim 39 \mathrm{~h}$, respectively (as shown in Fig. 5a, b). The temperature spatial structures corresponding to these E2 periods ( $~ 38$ and $\sim 39 \mathrm{~h})$ are presented in Fig. $5 \mathrm{c}$ and $\mathrm{d}$. The temperature spatial structure of E2 shows an obvious amplitude bimodal structure at $\sim 60-70^{\circ} \mathrm{S}$ and $\sim 50 \mathrm{~km}$ and $\sim 60-70^{\circ} \mathrm{S}$ and $\sim 60 \mathrm{~km}$, with the maximum at $\sim 60-70^{\circ} \mathrm{S}$ and $\sim 50 \mathrm{~km}$. The maximum temperature amplitude of E1 occurs at $\sim 50 \mathrm{~km}$ and $\sim 60-70^{\circ} \mathrm{S}$ with an amplitude of $\sim 7.5 \mathrm{~K}$ on days $173-178$, and the other peak is $\sim 6 \mathrm{~K}$ $\left(\sim 70^{\circ} \mathrm{S}\right.$ and $\left.\sim 60 \mathrm{~km}\right)$. The temperature amplitude of $\sim 10 \mathrm{~K}$ happens at $\sim 50 \mathrm{~km}$ and $\sim 60-70^{\circ} \mathrm{S}$ during days $219-224$, and the other events have a temperature amplitude of $\sim 6 \mathrm{~K}$ $\left(\sim 70^{\circ} \mathrm{S}\right.$ and $\left.\sim 60 \mathrm{~km}\right)$. The corresponding spatial structures of zonal wind and meridional wind of these E2 events are illustrated in Fig. 5e-h. The zonal wind spatial structure of E2 shows an obvious amplitude bimodal structure at $\sim 50-60^{\circ} \mathrm{S}$ and $\sim 60 \mathrm{~km}$ and $\sim 70-80^{\circ} \mathrm{S}$ and $\sim 60 \mathrm{~km}$, with the maximum at $\sim 50-60^{\circ} \mathrm{S}$ and $\sim 60 \mathrm{~km}$. The maximum zonal wind amplitude of E2 appears at $\sim 50-60^{\circ} \mathrm{S}$ and $\sim 60 \mathrm{~km}$ with an amplitude of $\sim 10 \mathrm{~m} / \mathrm{s}$ on days $173-178$, and the other peak is $\sim 9 \mathrm{~m} / \mathrm{s}\left(\sim 70-80^{\circ} \mathrm{S}\right.$ and $\left.\sim 60 \mathrm{~km}\right)$. The zonal wind amplitude of $\sim 20 \mathrm{~m} / \mathrm{s}$ occurs at $\sim 50-60^{\circ} \mathrm{S}$ and $\sim 60 \mathrm{~km}$ on days 219-224, and the other events have a zonal wind amplitude of $\sim 15 \mathrm{~m} / \mathrm{s}\left(\sim 70-80^{\circ} \mathrm{S}\right.$ and $\left.\sim 60 \mathrm{~km}\right)$. The amplitude of E2 meridional wind reaches $\sim 13 \mathrm{~m} / \mathrm{s}$ at $\sim 70-80^{\circ} \mathrm{S}$ and $\sim 60 \mathrm{~km}$ (days $173-178$ ) and $\sim 27 \mathrm{~m} / \mathrm{s}$ at $\sim 70-80^{\circ} \mathrm{S}$ and $\sim 60 \mathrm{~km}$ (days 219-224).

Figure $5 \mathrm{i}$ and $\mathrm{j}$ illustrate the diagnostic analysis during days 173-178 and 219-224, respectively, for E2. Obviously, $\mathrm{E} 2$ is more likely to propagate in the SH winter and is dramatically amplified by the mean flow instabilities at the middlehigh latitudes between $\sim 40$ and $\sim 80 \mathrm{~km}$. With EP flux propagating into the lower atmosphere, it eventually propagates 
(a) Temp spectrum Day 187-196

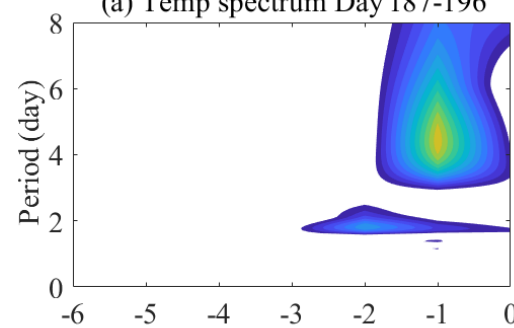

(c) Temp Structure of $106 \mathrm{~h}$

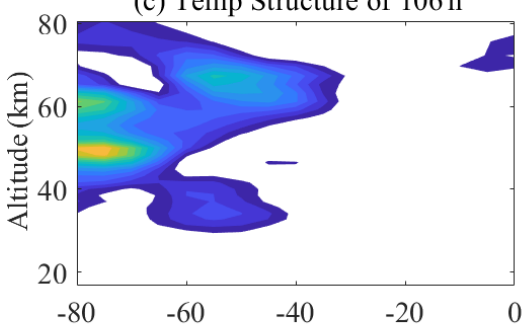

(e) Zonal Wind Structure of $106 \mathrm{~h}$

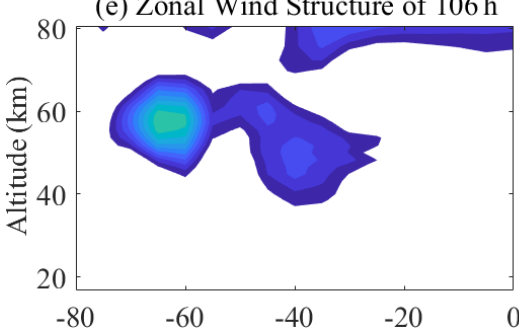

(g) Merid Wind Structure of $106 \mathrm{~h}$

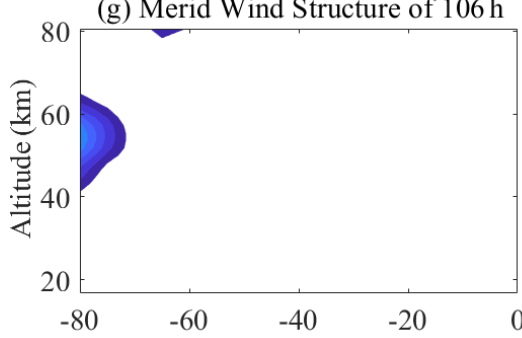

(i) Diagnostic analysis Day $187-196$

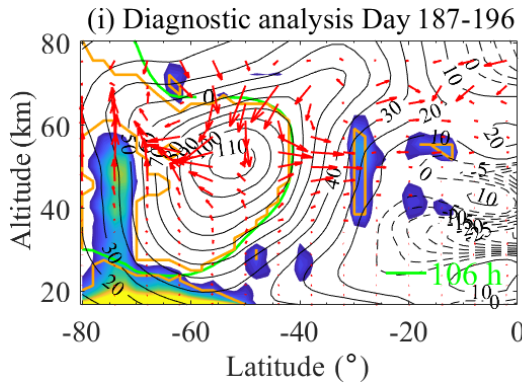

(b) Temp spectrum Day 211-220

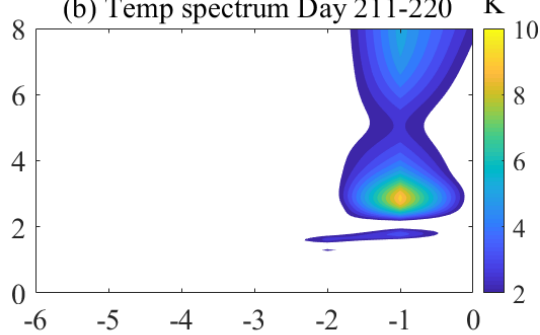

(d) Temp Structure of $69 \mathrm{~h}$

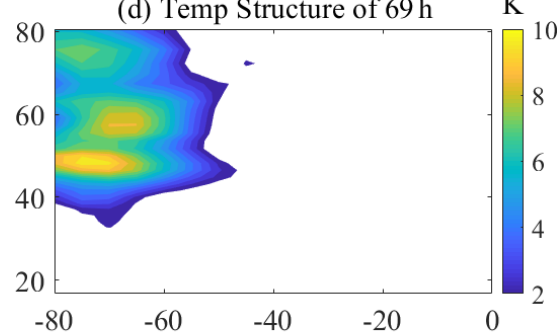

(f) Zonal Wind Structure of $69 \mathrm{~h} \mathrm{~m} / \mathrm{s}$

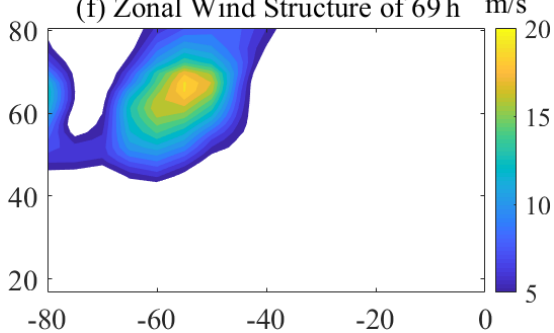

(h) Merid Wind Structure of $69 \mathrm{~h} \mathrm{~m} / \mathrm{s}$

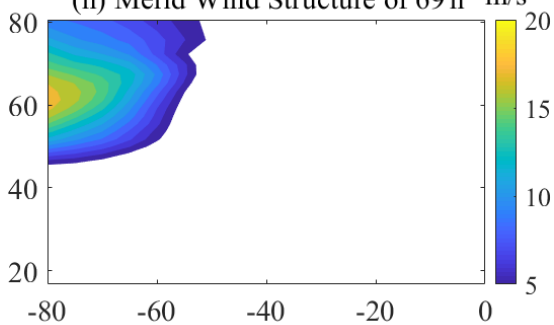

(j) Diagnostic analysis Day $211-220$ e-5

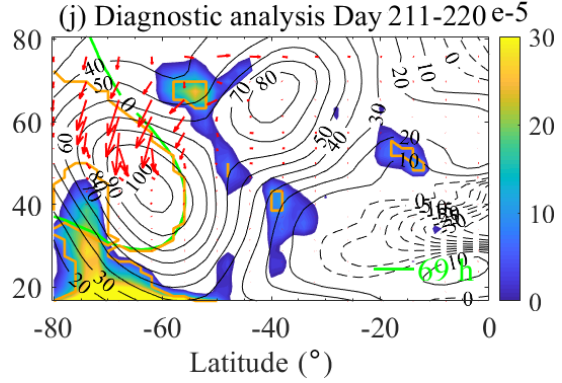

Figure 4. The (a, b) spectra, (c, d) temperature spatial structures, (e, f) zonal wind spatial structures, (g, h) meridional wind spatial structures and (i, j) diagnostic analysis of the E1 typical events during the 2019 austral winter period. The MERRA-2 temperature data observations at $48.2 \mathrm{~km}$ and $70-80^{\circ} \mathrm{S}$ during days 187-196 (Fig. 4a), 211-220 (Fig. 4d) are utilized. In the diagnostic analysis of E1 events, the blue-shaded regions are instability, the red arrows are EP flux, and the green line is the critical layer. The green line represents critical layers of E1 with the natural period. Regions enclosed by solid orange lines are characterized by the positive refractive index for E1. 
(a) Temp spectrum Day $173-178$

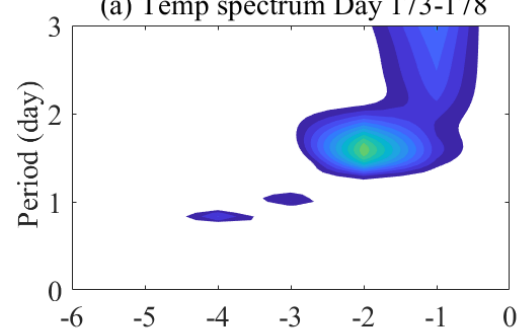

(c) Temp Structure of $38 \mathrm{~h}$

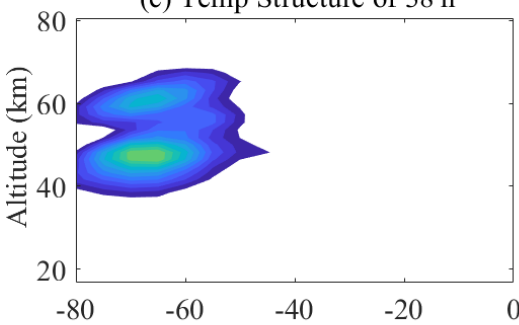

(e) Zonal Wind Structure of $38 \mathrm{~h}$

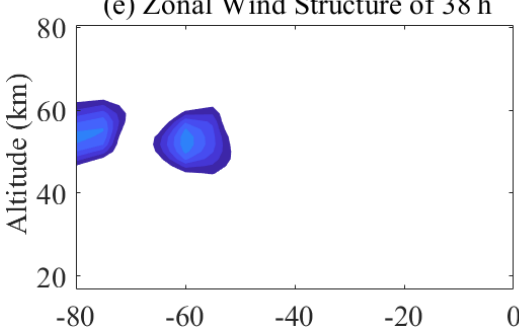

(g) Merid Wind Structure of $38 \mathrm{~h}$

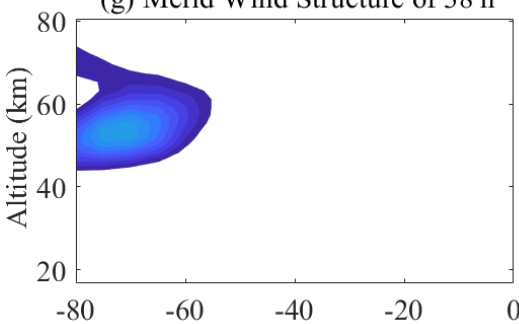

(i) Diagnostic analysis Day $173-178$

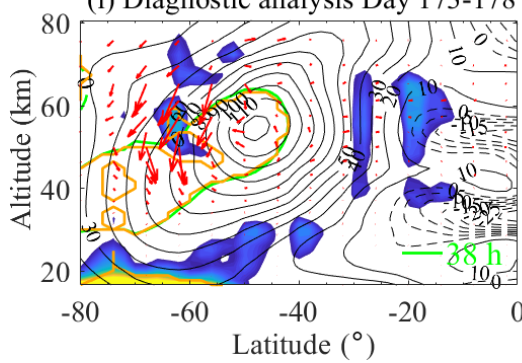

(b) Temp spectrum Day 219-224

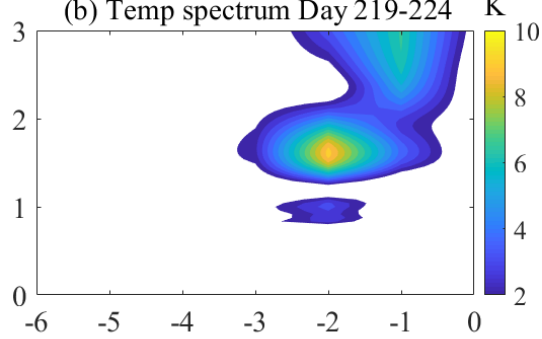

(d) Temp Structure of $39 \mathrm{~h} \quad \mathrm{~K}$
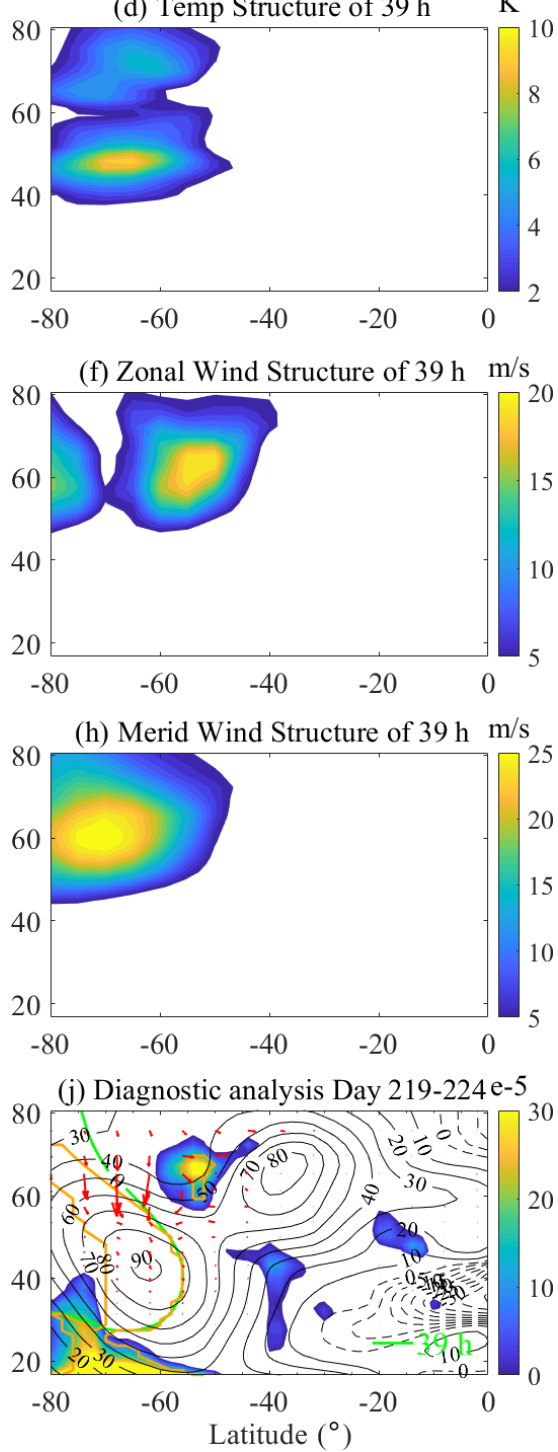

Figure 5. Same as Fig. 4 but for E2 during the 2019 austral winter period.

toward the Equator at $\sim 50 \mathrm{~km}$. Besides, E2 is amplified and propagated by the wave-mean flow interactions near its critical layer $(\sim 38 \mathrm{~h})$ of the green curve and the promoting effect of the positive-refractive-index region surrounded by the yellow curve. Meanwhile, the weak instability and strong background wind at $\sim 50-60^{\circ} \mathrm{S}$ and $\sim 50-70 \mathrm{~km}$ provide the energy for the propagation and amplification of EP flux into the lower atmosphere during days 173-178 (Fig. 5i). According to the diagnostic analysis of days 219-224, E2 obtains sufficient energy from strong instability and strong background wind at $\sim 50-60^{\circ} \mathrm{S}$ and $\sim 60-70 \mathrm{~km}$. It is amplified and propagated into the lower atmosphere through the critical layer and positive-refractive-index action (as shown in Fig. 5j). The results show that the background wind at $\sim 50$ 
$60^{\circ} \mathrm{S}$ and $\sim 50-70 \mathrm{~km}$ is weaker on days $173-178$ than on days 219-224; and the instability at $\sim 50-60^{\circ} \mathrm{S}$ and $\sim 60$ $70 \mathrm{~km}$ is stronger on days 219-224 than on days 173-178. Our results show that E2 has absorbed sufficient energy to be amplified under the background conditions during days 219224 (Fig. 5a, b).

Figure $6 \mathrm{a}$ and $\mathrm{b}$ show the observed spectra of E3 at $\sim 48.2 \mathrm{~km}$ and $\sim 60-70^{\circ} \mathrm{S}$ on days $151-154$ and $201-204$, and the wave periods of locked wavenumber -3 are $\sim 29$ and $\sim 29 \mathrm{~h}$, respectively. The corresponding temperature spatial structures of these E3 periods (i.e., $\sim 29$ and $\sim 29 \mathrm{~h}$ ) are displayed in Fig. 6c and d. The temperature spatial structure of $\mathrm{E} 3$ shows an obvious amplitude bimodal structure at $\sim 60-70^{\circ} \mathrm{S}$ and $\sim 50 \mathrm{~km}$, and $\sim 60-70^{\circ} \mathrm{S}$ and $\sim 60 \mathrm{~km}$, with the maximum at $\sim 60-70^{\circ} \mathrm{S}$ and $\sim 50 \mathrm{~km}$. Besides, E3 also has a weak peak at $\sim 60-70^{\circ} \mathrm{S}$ and $\sim 70 \mathrm{~km}$. The strongest temperature amplitude of E3 occurs at $\sim 50 \mathrm{~km}$ and $\sim 60$ $70^{\circ} \mathrm{S}$ with an amplitude of $\sim 6 \mathrm{~K}$ on days $151-154$, and the other peak is $\sim 5 \mathrm{~K}\left(\sim 60-70^{\circ} \mathrm{S}\right.$ and $\left.\sim 60 \mathrm{~km}\right)$. The temperature amplitude of $\sim 5 \mathrm{~K}$ happens at $\sim 50 \mathrm{~km}(\sim 60 \mathrm{~km})$ and $\sim 60-70^{\circ} \mathrm{S}$ during days $201-204$. The corresponding spatial structures of zonal wind and meridional wind of these E3 events are shown in Fig. 6e-h. The zonal wind spatial structure of E3 shows an obvious amplitude bimodal structure at $\sim 70-80^{\circ} \mathrm{S}$ and $\sim 60 \mathrm{~km}$ and $\sim 50-60^{\circ} \mathrm{S}$ and $\sim 60 \mathrm{~km}$. The zonal wind amplitudes of $\mathrm{E} 3$ occur at $\sim 70-80^{\circ} \mathrm{S}$ and $\sim 60 \mathrm{~km}\left(\sim 50-60^{\circ} \mathrm{S}\right.$ and $\left.\sim 60 \mathrm{~km}\right)$ with an amplitude of $\sim 9 \mathrm{~m} / \mathrm{s}$ on days $151-154$ and $\sim 9 \mathrm{~m} / \mathrm{s}$ at $\sim 70-80^{\circ} \mathrm{S}$ and $\sim 60 \mathrm{~km}\left(\sim 50-60^{\circ} \mathrm{S}\right.$ and $\left.\sim 60 \mathrm{~km}\right)$ on days $201-204$. The amplitude of E3 meridional wind hits $\sim 13 \mathrm{~m} / \mathrm{s}$ at $\sim 60-70^{\circ} \mathrm{S}$ and $\sim 55 \mathrm{~km}$ (days $151-154$ ) and $\sim 16 \mathrm{~m} / \mathrm{s}$ at $\sim 60-70^{\circ} \mathrm{S}$ and $\sim 55 \mathrm{~km}$ (days 201-204).

The EP flux of E3 is similar to that of E2. The instability and appropriate background wind at the middle-high latitudes between $\sim 50 \mathrm{~km}$ and $\sim 70 \mathrm{~km}$ dramatically amplify the propagation of $\mathrm{E} 3$, which is enhanced by the interaction near the critical layer $(\sim 29 \mathrm{~h})$ and the positive-refractiveindex region (Fig. 6i and j). Notably, the strong instability and weak background wind at $\sim 50-60^{\circ} \mathrm{S}$ and $\sim 60-70 \mathrm{~km}$ on days 151-154 provide sufficient energy for the propagation and amplification of EP flux into the lower atmosphere and ultimately point toward the Equator at $50 \mathrm{~km}$. During days 201-204, the EP flux propagates into the lower atmosphere and is amplified by interaction at the critical layer $(\sim 29 \mathrm{~h})$. Besides, weak instability and weak background wind at $\sim 50-60^{\circ} \mathrm{S}$ and $\sim 60-70 \mathrm{~km}$ provide the energy to amplify the E3 propagation. Figure $6 \mathrm{c}$ and dindicate that the stronger the instability at $\sim 50-60^{\circ} \mathrm{S}$ and $\sim 60-70 \mathrm{~km}$, the stronger the temperature amplitude of $\mathrm{E} 3$. We believe that the background wind and instability at $\sim 50-60^{\circ} \mathrm{S}$ and $\sim 60$ $70 \mathrm{~km}$ are the main reasons for the propagation and amplification of EP flux into the lower atmosphere.

For E4, the spectra appear at $\sim 48.2 \mathrm{~km}$ and $\sim 50-60^{\circ} \mathrm{S}$ on days 127-130 and 213-216 when the eastward wavenumber -4 signal has a wave period of $\sim 25$ and $\sim 21 \mathrm{~h}$ (see
Fig. 7a, b). The corresponding temperature spatial structures of these E4 periods (i.e., $\sim 25$ and $\sim 21 \mathrm{~h}$ ) are shown in Fig. $7 \mathrm{c}$ and d. The temperature spatial structure of E4 shows an obvious amplitude bimodal structure at $\sim 50-60^{\circ} \mathrm{S}$ and $\sim 50 \mathrm{~km}$ and $\sim 50-60^{\circ} \mathrm{S}$ and $\sim 60 \mathrm{~km}$, with the maximum at $\sim 50-60^{\circ} \mathrm{S}$ and $\sim 50 \mathrm{~km}$. The maximum temperature amplitude of E4 occurs at $\sim 50 \mathrm{~km}$ and $\sim 50-60^{\circ} \mathrm{S}$ with an amplitude of $\sim 4 \mathrm{~K}$ on days $127-130$, and the other peak is $\sim 3 \mathrm{~K}\left(\sim 60-70^{\circ} \mathrm{S}\right.$ and $\left.\sim 60 \mathrm{~km}\right)$. The temperature amplitude of $\sim 3 \mathrm{~K}$ occurs at $\sim 50 \mathrm{~km}(\sim 60 \mathrm{~km})$ during days $213-$ 216 . The corresponding spatial structures of zonal wind and meridional wind of these E4 events are presented in Fig. 7e$\mathrm{h}$. The zonal wind spatial structure of E4 shows an obvious amplitude bimodal structure at $\sim 50-60^{\circ} \mathrm{S}$ and $\sim 55 \mathrm{~km}$ and $\sim 60-70^{\circ} \mathrm{S}$ and $\sim 55 \mathrm{~km}$, with the maximum at $\sim 50$ $60^{\circ} \mathrm{S}$ and $\sim 55 \mathrm{~km}$. The maximum zonal wind amplitude of E4 happens at $\sim 50-60^{\circ} \mathrm{S}$ and $\sim 55 \mathrm{~km}$ with an amplitude of $\sim 9 \mathrm{~m} / \mathrm{s}$ on days $127-130$, and the other peak is $\sim 5 \mathrm{~K}(\sim 60$ $70^{\circ} \mathrm{S}$ and $\left.\sim 55 \mathrm{~km}\right)$. The zonal wind amplitude of $\sim 5 \mathrm{~m} / \mathrm{s} \mathrm{oc-}$ curs at $\sim 50-60^{\circ} \mathrm{S}\left(\sim 60-70^{\circ} \mathrm{S}\right)$ and $\sim 55 \mathrm{~km}$ on days $213-$ 216. The amplitude of E4 meridional wind reaches $\sim 8 \mathrm{~m} / \mathrm{s}$ at $\sim 60-70^{\circ} \mathrm{S}$ and $\sim 55 \mathrm{~km}$ (days $127-130$ ) and $\sim 10 \mathrm{~m} / \mathrm{s}$ at $\sim 60-70^{\circ} \mathrm{S}$ and $\sim 55 \mathrm{~km}$ (days 213-216).

Diagnostic analysis for E4 on days 127-130 and 213-216 is shown in Fig. 7i and j, respectively. The results demonstrate that E4 is dramatically amplified by the mean flow instabilities at the middle-high latitudes between $\sim 50$ and $\sim 70 \mathrm{~km}$. With EP flux propagating into the lower atmosphere, it finally propagates toward the Equator at $\sim 50 \mathrm{~km}$. E4 is amplified and propagated by the wave-mean flow interaction near the critical layer $(\sim 25$ and $\sim 21 \mathrm{~h}$ ), and the positive-refractive-index region generates the promoting effect. The strong instability and weak background wind at $\sim 50-60^{\circ} \mathrm{S}$ and $\sim 60-70 \mathrm{~km}$ provide sufficient energy for the propagation and amplification of EP flux into the lower atmosphere during days 127-130. Besides, E4 obtains energy from weak instability and weak background wind at $\sim 50$ $60^{\circ} \mathrm{S}$ and $\sim 60-70 \mathrm{~km}$ on days $213-216$, and it is amplified and propagated into the lower atmosphere. The background wind at $\sim 50-60^{\circ} \mathrm{S}$ and $\sim 60-70 \mathrm{~km}$ on days $127-130$ is similar to on days $213-216$, and the instability at $\sim 50-60^{\circ} \mathrm{S}$ and $\sim 60-70 \mathrm{~km}$ is stronger on days $127-130$ than on days 213216. According to Fig. 7a and b, E4 absorbs sufficient energy to be amplified under the background conditions on days $127-130$, and the temperature amplitude on days $127-$ 130 is stronger.

\subsection{In the Northern Hemisphere}

Figure 8 shows that the observed maximum temperature amplitude appears at $\sim 59.2 \mathrm{~km}$ and $\sim 70-80^{\circ} \mathrm{N}$ for E1, and E2 and E3 peak at $\sim 59.2 \mathrm{~km}$ and $\sim 60-70^{\circ} \mathrm{N}$. The maximum perturbation of E1 occurs on days 41-50 (with an amplitude of $\sim 8 \mathrm{~K}$ ), while the remaining fluctuations occur on days 25-34 and 339-348. Besides, the strongest E2 event 
(a) Temp spectrum Day 151-154

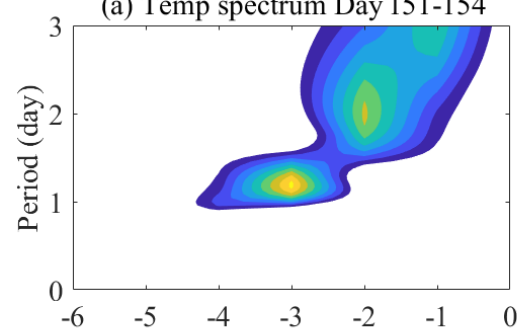

(c) Temp Structure of $29 \mathrm{~h}$

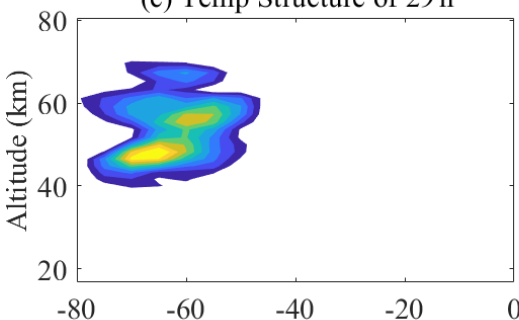

(e) Zonal Wind Structure of $29 \mathrm{~h}$

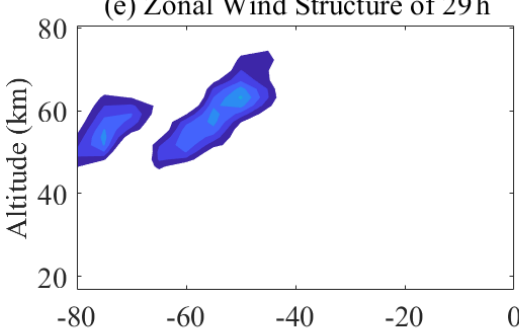

(g) Merid Wind Structure of $29 \mathrm{~h}$

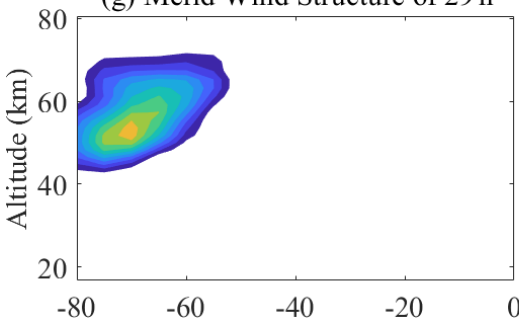

(i) Diagnostic analysis Day 151-154

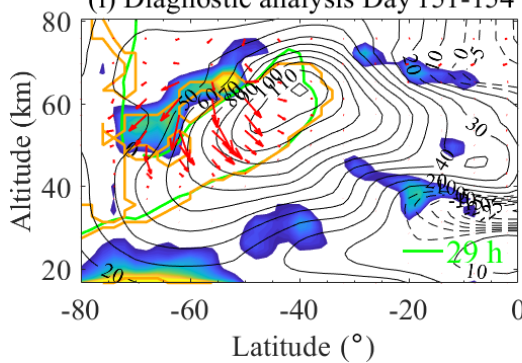

(b) Temp spectrum Day201-204

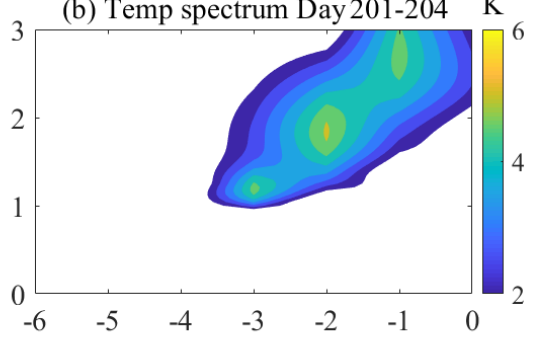

(d) Temp Structure of $29 \mathrm{~h} \quad \mathrm{~K}$
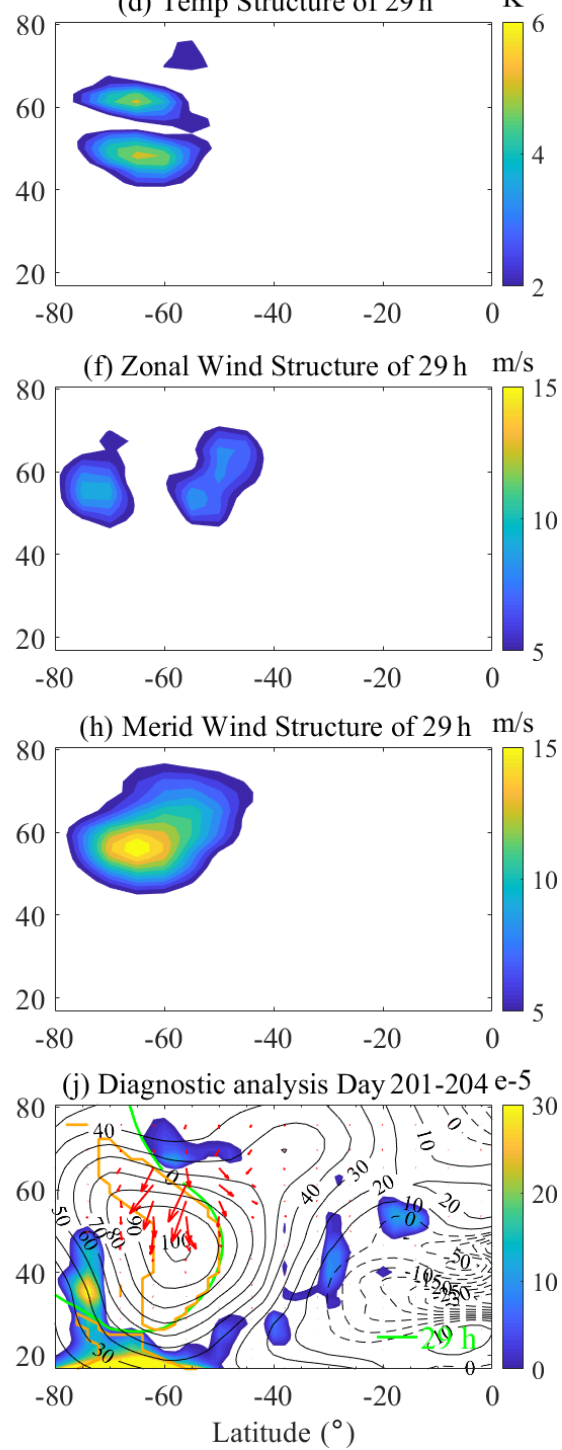

Figure 6. Same as Fig. 4 but for E3 during the 2019 austral winter period.

occurs on days 69-74 (with an amplitude of $\sim 7 \mathrm{~K}$ ), and the other events are distributed on days 25-30,317-322 and 341-346. By contrast, E3 is maximal on days 35-38 (with an amplitude of $\sim 3 \mathrm{~K}$ ) and also shows a peak on days 53-56. Based on the study of the wave period in the SH for eastward waves, the periodic variabilities in E1, E2 and E3 in the $\mathrm{NH}$ are also examined. The wave period of $\mathrm{E} 1$ decreases from a maximum of $\sim 118 \mathrm{~h}$ (days $25-34$ ) to $\sim 80 \mathrm{~h}$ (days $41-50$ ), indicating the instability of the wave period of $\mathrm{E} 1$ in the $\mathrm{NH}$. The E2 events occur on days 25-30, 69-74, 317-322 and $341-346$, of which the corresponding wave periods are $\sim 36$, $\sim 53, \sim 52$ and $\sim 48 \mathrm{~h}$, which are stronger and more stable than E1. Besides, the wave period of E3 is relatively stable at 
(a) Temp spectrum Day 127-130

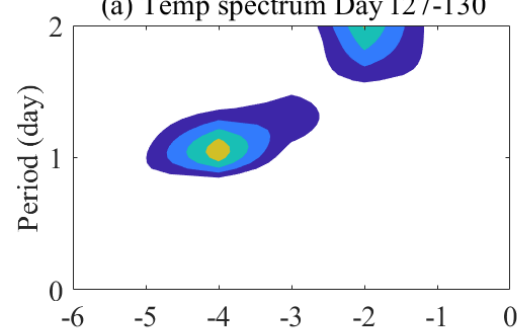

(c) Temp Structure of $25 \mathrm{~h}$

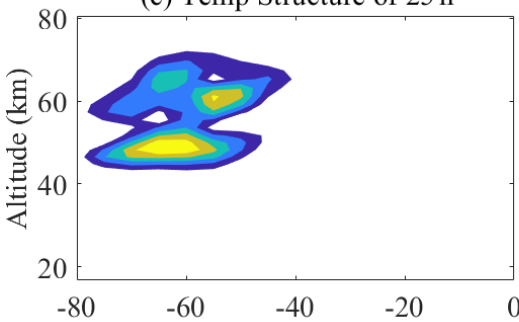

(e) Zonal Wind Structure of $25 \mathrm{~h}$

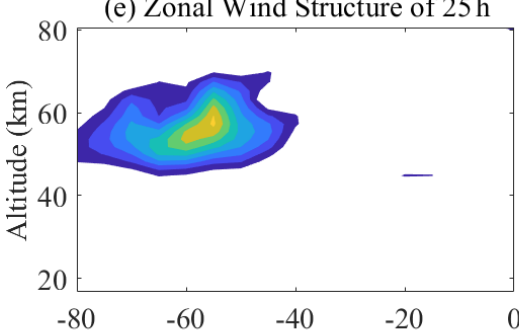

(g) Merid Wind Structure of $25 \mathrm{~h}$

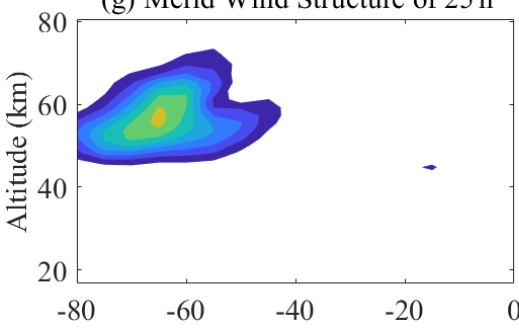

(i) Diagnostic analysis Day $127-130$

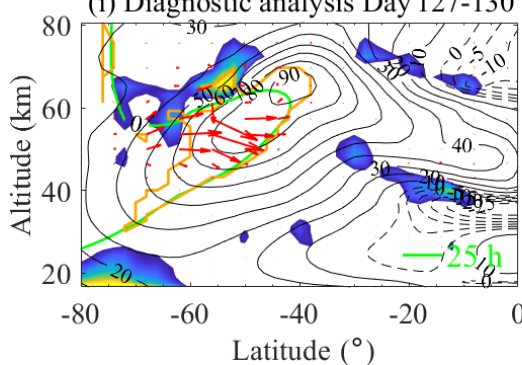

(b) Temp spectrum Day213-216 K

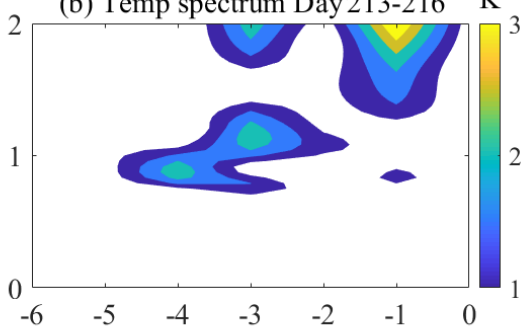

(d) Temp Structure of $21 \mathrm{~h} \quad \mathrm{~K}$
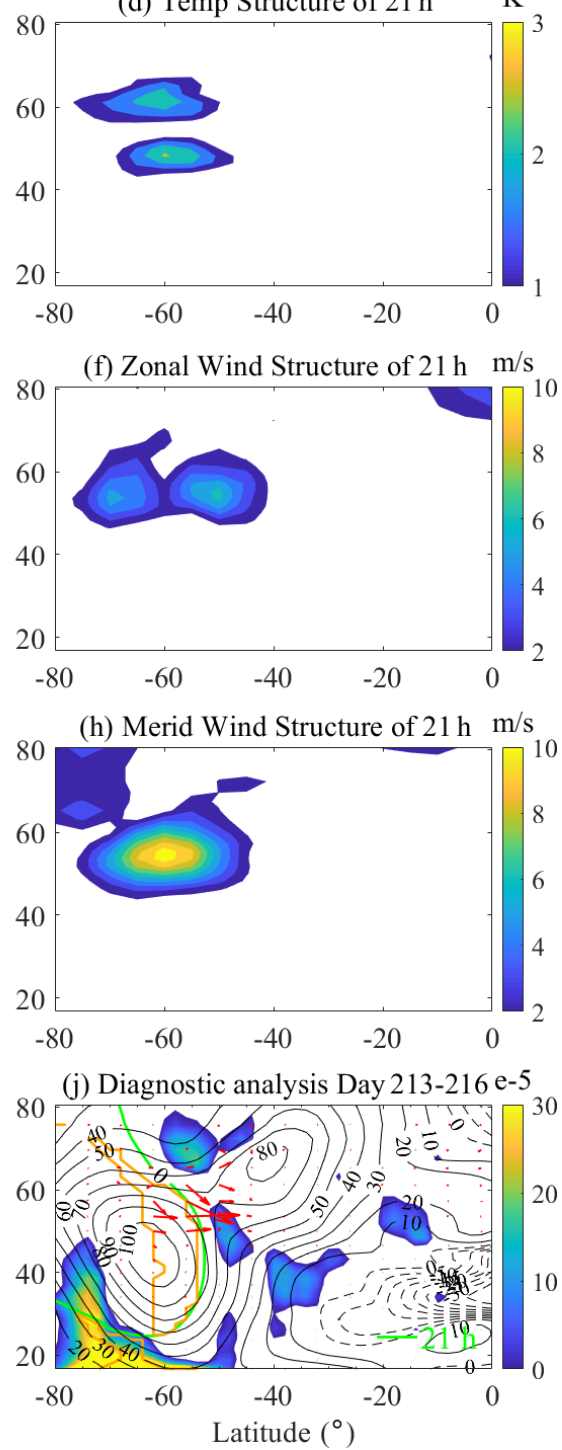

Figure 7. Same as Fig. 4 but for E4 during the 2019 austral winter period.

$\sim 29$ and $\sim 27 \mathrm{~h}$. Thus, the E2 and E3 wave periods are more stable than that of E1.

The spectra, spatial (vertical and latitudinal) structures of temperature, zonal and meridional wind, and diagnostic analysis of E1 are extracted from the corresponding representative events (as shown in Fig. 9). Figure 9a and b show the observed spectra of E1 at $\sim 59.2 \mathrm{~km}$ and $\sim 70-80^{\circ} \mathrm{N}$ on days 25-34 and 41-50, and the wave periods of locked wavenumber -1 are $\sim 118$ and $\sim 80 \mathrm{~h}$, respectively. The corresponding temperature spatial structures of these E1 periods $(\sim 118$ and $\sim 80 \mathrm{~h})$ are shown in Fig. $9 \mathrm{c}$ and $\mathrm{d}$. The temperature spatial structure of E1 shows an obvious amplitude bimodal structure during days $25-34$ at $\sim 60-70^{\circ} \mathrm{N}$ and $\sim 60 \mathrm{~km}$ and $\sim 40-50^{\circ} \mathrm{N}$ and $\sim 70 \mathrm{~km}$, with the maximum 
(a) Temperature $\mathrm{E} 1$ amplitude at $70-80^{\circ} \mathrm{N}$ and $59.2 \mathrm{~km} \mathrm{~K}$

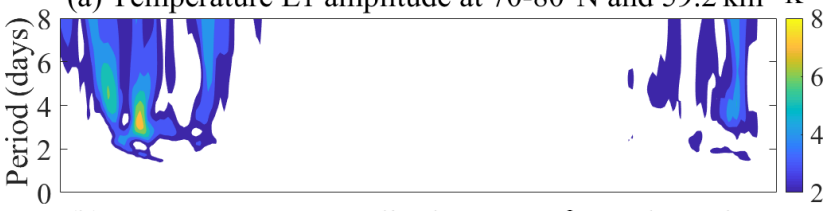

(b) Temperature E2 amplitude at $60-70^{\circ} \mathrm{N}$ and $59.2 \mathrm{~km} \mathrm{~K}$

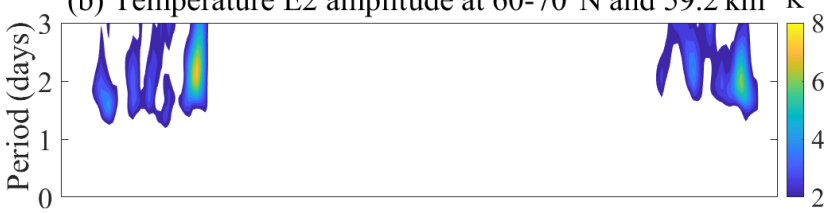

(c) Temperature E3 amplitude at $60-70^{\circ} \mathrm{N}$ and $59.2 \mathrm{~km} \mathrm{~K}$

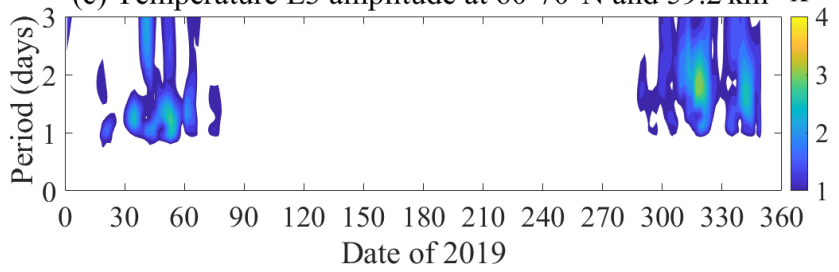

Figure 8. The temporal variations in (a) E1, (b) E2 and (c) E3 QTDWs during the 2019 boreal winter period. The date indicates the day of the year.

at $\sim 60-70^{\circ} \mathrm{N}$ and $\sim 60 \mathrm{~km}$. On top of that, E1 also has bimodal structure on days $41-50$ at $\sim 60-70^{\circ} \mathrm{N}$ and $\sim 60 \mathrm{~km}$ and $\sim 60-70^{\circ} \mathrm{N}$ and $\sim 70 \mathrm{~km}$. The strongest temperature amplitude of E1 occurs at $\sim 60-70^{\circ} \mathrm{N}$ and $\sim 60 \mathrm{~km}$ with an amplitude of $\sim 7 \mathrm{~K}$ on days $25-34$, and the other peak is $\sim 4 \mathrm{~K}\left(\sim 40-50^{\circ} \mathrm{N}\right.$ and $\left.\sim 70 \mathrm{~km}\right)$. The temperature amplitude of $\sim 10 \mathrm{~K}$ occurs at $\sim 60 \mathrm{~km}$ and $\sim 60-70^{\circ} \mathrm{N}$ during days $41-50$, and the other events have a temperature amplitude of $\sim 8 \mathrm{~K}\left(\sim 60-70^{\circ} \mathrm{N}\right.$ and $\left.\sim 70 \mathrm{~km}\right)$. The corresponding spatial structures of zonal wind and meridional wind of these E1 events are illustrated in Fig. 9e-h. The zonal wind spatial structure of $\mathrm{E} 1$ presents an obvious amplitude bimodal structure at $\sim 70-80^{\circ} \mathrm{N}$ and $\sim 70 \mathrm{~km}$ and $\sim 50$ $60^{\circ} \mathrm{N}$ and $\sim 70 \mathrm{~km}$. The zonal wind amplitude of $\sim 13 \mathrm{~m} / \mathrm{s}$ occurs at $\sim 70-80^{\circ} \mathrm{N}$ and $\sim 70 \mathrm{~km}$ on days $25-34$, and the other events have a zonal wind amplitude of $\sim 10 \mathrm{~m} / \mathrm{s}(\sim 50$ $60^{\circ} \mathrm{N}$ and $\left.\sim 70 \mathrm{~km}\right)$. In addition, there is a weak peak of $9 \mathrm{~K}$ during days $25-34\left(\sim 30-40^{\circ} \mathrm{N}\right.$ and $\left.\sim 70 \mathrm{~km}\right)$. The maximum zonal wind amplitude of E1 occurs at $\sim 70-80^{\circ} \mathrm{N}$ and $\sim 70 \mathrm{~km}$ with an amplitude of $\sim 19 \mathrm{~m} / \mathrm{s}$ on days $41-50$, and the other peak is $\sim 13 \mathrm{~K}\left(\sim 50-60^{\circ} \mathrm{N}\right.$ and $\left.\sim 70 \mathrm{~km}\right)$. The amplitude of E1 meridional wind hits $\sim 14 \mathrm{~m} / \mathrm{s}$ at $\sim 70-80^{\circ} \mathrm{N}$ and $\sim 70 \mathrm{~km}$ (days $25-34$ ) and $\sim 22 \mathrm{~m} / \mathrm{s}$ at $\sim 70-80^{\circ} \mathrm{N}$ and $\sim 70 \mathrm{~km}$ (days $41-50$ ).

The diagnostic analysis results for E1 (in Fig. 9i and j) suggest the dramatic amplification of E1 by the mean flow instabilities at the middle-high latitudes between $\sim 50 \mathrm{~km}$ and $\sim 70 \mathrm{~km}$. With the propagation of EP flux into the polar lower atmosphere, it eventually propagates toward the Equator at $\sim 50 \mathrm{~km}$. The wave-mean flow interaction near the critical layers $(\sim 118$ and $\sim 80 \mathrm{~h})$ amplifies and propagates
E1, and the promoting effect of the positive-refractive-index region amplifies E1. Furthermore, the weak instability and strong background wind at $\sim 40-50^{\circ} \mathrm{N}$ and $\sim 60-70 \mathrm{~km}$ generate the energy for the propagation and amplification of EP flux into the polar lower atmosphere during days 25-34. E1 obtains sufficient energy from weak instability and suitable background wind on days $41-50$ at $\sim 40-50^{\circ} \mathrm{N}$ and $\sim 60$ $70 \mathrm{~km}$ and is amplified and propagated into the polar lower atmosphere through the critical layer and positive-refractiveindex action. The background wind at $\sim 40-50^{\circ} \mathrm{N}$ and $\sim 60$ $70 \mathrm{~km}$ is stronger on days $25-34$ than on days $41-50$, but its instability is similar, indicating that stronger background winds might weaken E1 propagation and amplification at the middle-northern latitudes. Our results show that E1 absorbs adequate energy to be amplified under the background conditions during days $41-50$, reflecting a stronger temperature amplitude (see Fig. 9a, b).

For E2, the spectra are at $\sim 59.2 \mathrm{~km}$ and $\sim 60-70^{\circ} \mathrm{N}$ on days $25-30$ and $69-74$ when the eastward wavenumber -2 signal has the periods $\sim 36$ and $\sim 53 \mathrm{~h}$ (as shown in Fig. 10a, b). The corresponding temperature spatial structures of these E2 periods (i.e., $\sim 36$ and $\sim 53 \mathrm{~h}$ ) are presented in Fig. 10c and $d$. The temperature spatial structure of E2 demonstrates an obvious amplitude bimodal structure at $\sim 60-70^{\circ} \mathrm{N}$ and $\sim 60 \mathrm{~km}$, and $\sim 60-70^{\circ} \mathrm{N}$ and $\sim 70 \mathrm{~km}$, with the maximum at $\sim 60-70^{\circ} \mathrm{N}$ and $\sim 60 \mathrm{~km}$. The maximum temperature amplitude of E2 occurs at $\sim 60-70^{\circ} \mathrm{N}$ and $\sim 60 \mathrm{~km}$ with an amplitude of $\sim 5 \mathrm{~K}$ on days $25-30$, and the other peak is $\sim 4 \mathrm{~K}$ $\left(\sim 60-70^{\circ} \mathrm{N}\right.$ and $\left.\sim 70 \mathrm{~km}\right)$. The temperature amplitude of $\sim 9 \mathrm{~K}$ occurs on days $69-74$ at $\sim 60^{\circ} \mathrm{S}$ and $\sim 60 \mathrm{~km}$, and the other peaks are $\sim 7 \mathrm{~K}\left(\sim 60-70^{\circ} \mathrm{N}\right.$ and $\left.\sim 70 \mathrm{~km}\right)$ and $\sim 5 \mathrm{~K}$ $\left(\sim 60-70^{\circ} \mathrm{N}\right.$ and $\left.\sim 50 \mathrm{~km}\right)$. The corresponding spatial structures of zonal wind and meridional wind of these E2 events are shown in Fig. 10e-h. The zonal wind spatial structure of E2 shows an obvious amplitude bimodal structure at $\sim 60$ $70^{\circ} \mathrm{N}$ and $\sim 60 \mathrm{~km}$ and $\sim 40-50^{\circ} \mathrm{N}$ and $\sim 60 \mathrm{~km}$, with the maximum at $\sim 40-50^{\circ} \mathrm{N}$ and $\sim 60 \mathrm{~km}$. The maximum zonal wind amplitude of E2 appears at $\sim 60-70^{\circ} \mathrm{N}$ and $\sim 60 \mathrm{~km}$ $\left(\sim 40-50^{\circ} \mathrm{N}\right.$ and $\left.\sim 60 \mathrm{~km}\right)$ with an amplitude of $\sim 6 \mathrm{~m} / \mathrm{s}$ on days $25-30$. Zonal wind amplitude occurs at $\sim 40-50^{\circ} \mathrm{N}$ and $\sim 60 \mathrm{~km}$ with an amplitude of $\sim 18 \mathrm{~m} / \mathrm{s}$ on days $41-50$, and the other peak is $\sim 16 \mathrm{~K}\left(\sim 60-70^{\circ} \mathrm{N}\right.$ and $\left.\sim 60 \mathrm{~km}\right)$. The amplitude of E2 meridional wind reaches $\sim 7 \mathrm{~m} / \mathrm{s}$ at $\sim 60-70^{\circ} \mathrm{N}$ and $\sim 70 \mathrm{~km}$ (days $25-30$ ) and $\sim 18 \mathrm{~m} / \mathrm{s}$ at $\sim 60-70^{\circ} \mathrm{N}$ and $\sim 60 \mathrm{~km}$ (days 41-50).

The diagnostic analysis of E2 on days 25-30 and 69-74 is shown in Fig. 10i and j, respectively. Apparently, E2 is significantly amplified by the mean flow instabilities at the middle-high latitudes between $\sim 40$ and $\sim 70 \mathrm{~km}$, with EP flux propagating into the polar lower atmosphere, and EP flux eventually propagates toward the Equator at $\sim 50 \mathrm{~km}$. E2 is amplified and propagated by the wave-mean flow interaction near the critical layers $(\sim 36$ and $\sim 53 \mathrm{~h})$, and the positive-refractive-index region provides the promoting effect. The weak instability and strong background wind at 
(a) Temp spectrum Day 25-34

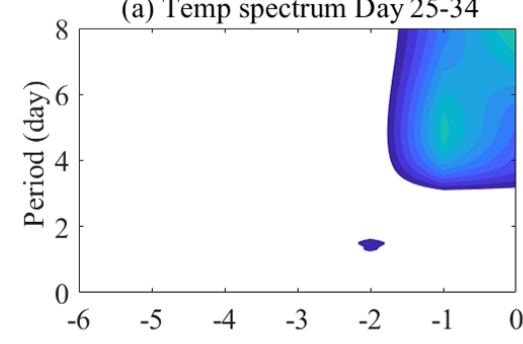

(c) Temp Structure of $118 \mathrm{~h}$

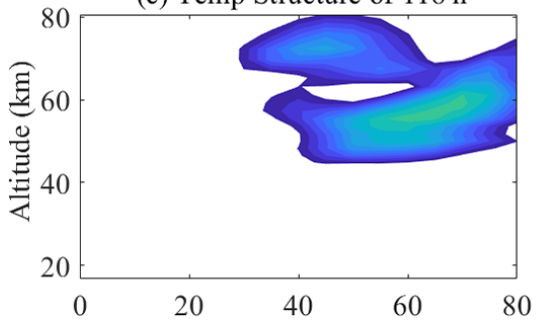

(e) Zonal Wind Structure of $118 \mathrm{~h}$

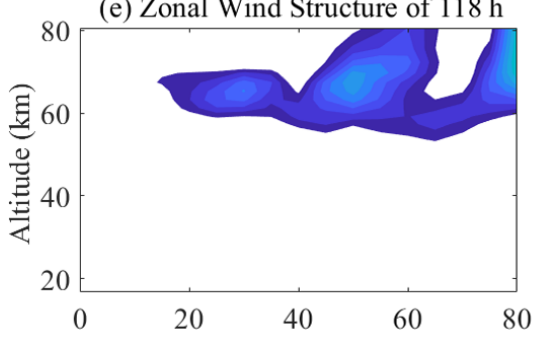

(g) Merid Wind Structure of $118 \mathrm{~h}$

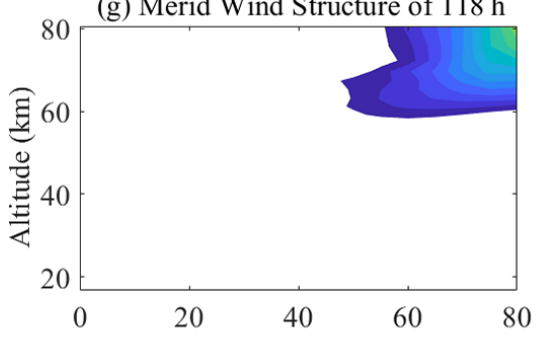

(i) Diagnostic analysis Day 25-34

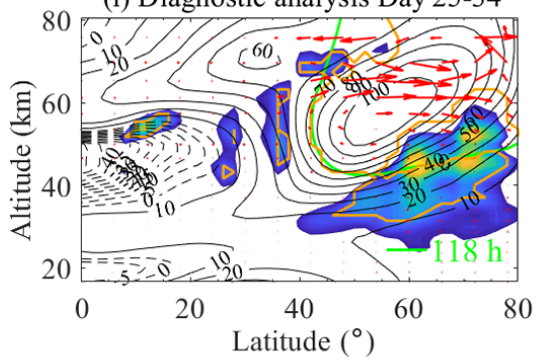

(b) Temp spectrum Day 41-50

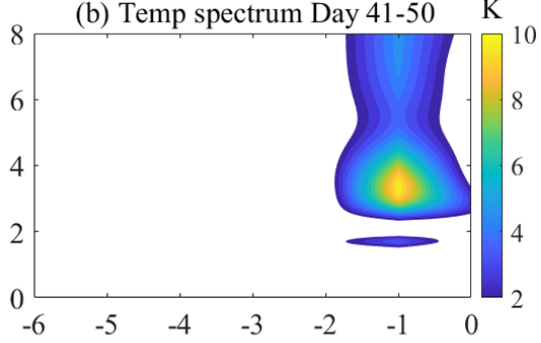

(d) Temp Structure of $80 \mathrm{~h} \quad \mathrm{~K}$

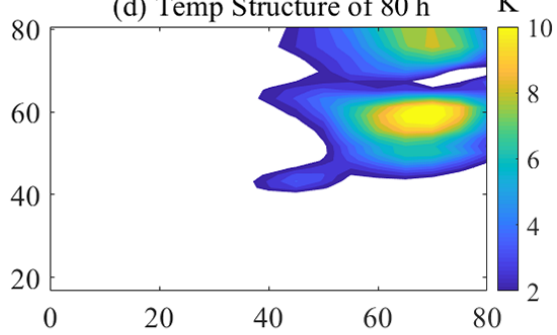

(f) Zonal Wind Structure of $80 \mathrm{~h} \mathrm{~m} / \mathrm{s}$

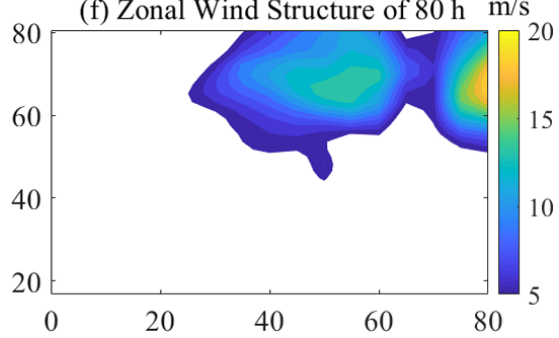

(h) Merid Wind Structure of $80 \mathrm{~h} \mathrm{~m} / \mathrm{s}$
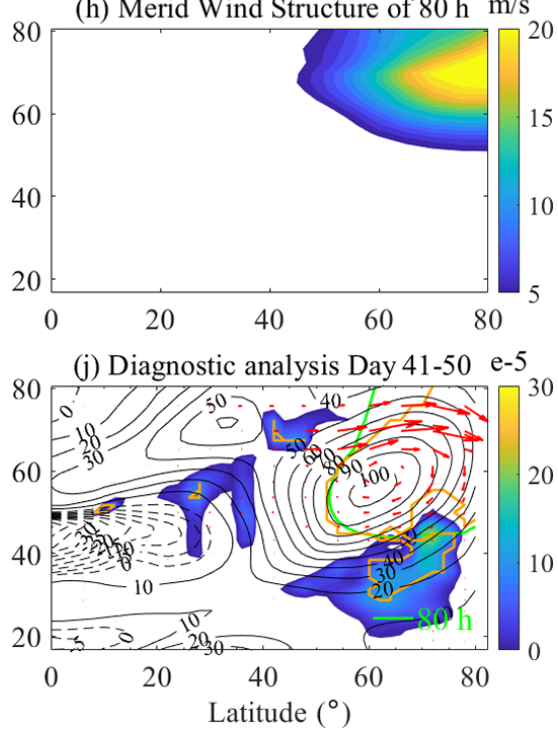

Figure 9. The (a, b) spectra, $(\mathbf{c}, \mathbf{d})$ temperature spatial structures, $(\mathbf{e}, \mathbf{f})$ zonal wind spatial structures, $(\mathbf{g}$, h) meridional wind spatial structures and (i, j) diagnostic analysis of the E1 typical events during the 2019 boreal winter period. The E1 events at $48.2 \mathrm{~km}$ and $70-80^{\circ} \mathrm{N}$ were obtained from the MERRA-2 reanalysis.

$\sim 50-60^{\circ} \mathrm{N}$ and $\sim 60-70 \mathrm{~km}$ provide the energy for the propagation and amplification of EP flux into the polar lower atmosphere during days 25-30. Moreover, E2 obtains sufficient energy from strong instability and suitable background wind at $\sim 50-60^{\circ} \mathrm{N}$ and $\sim 60-70 \mathrm{~km}$ on days $69-74$, and it is amplified and propagated into the polar lower atmosphere. The background wind at $\sim 50-60^{\circ} \mathrm{N}$ and $\sim 60-70 \mathrm{~km}$ on days $127-130$ is similar to on days $213-216$, and the instability at $\sim 50-60^{\circ} \mathrm{S}$ and $\sim 60-70 \mathrm{~km}$ is stronger on days $127-$ 30 than on days 213-216. Although the background wind 
(a) Temp spectrum Day 25-30

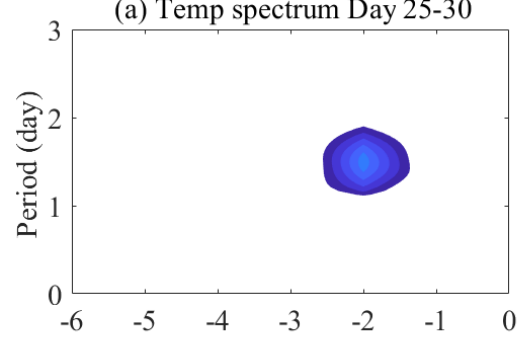

(c) Temp Structure of $36 \mathrm{~h}$

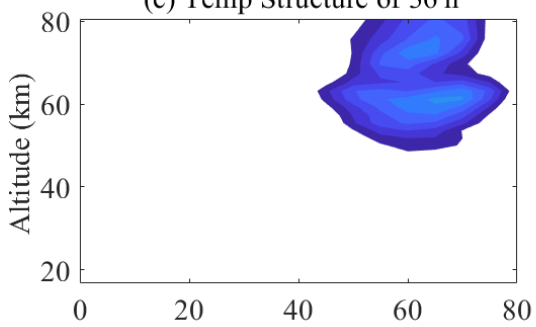

(e) Zonal Wind Structure of $36 \mathrm{~h}$

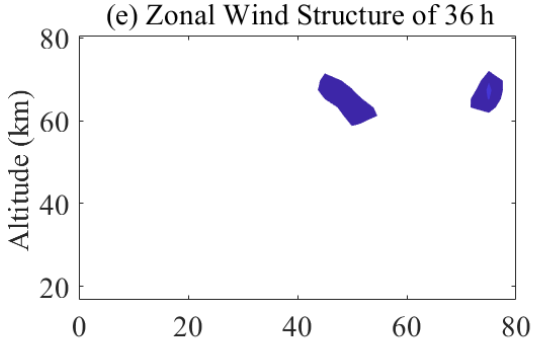

(g) Merid Wind Structure of $36 \mathrm{~h}$

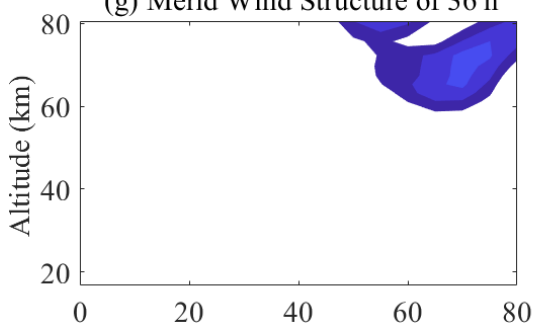

(i) Diagnostic analysis Day 25-30

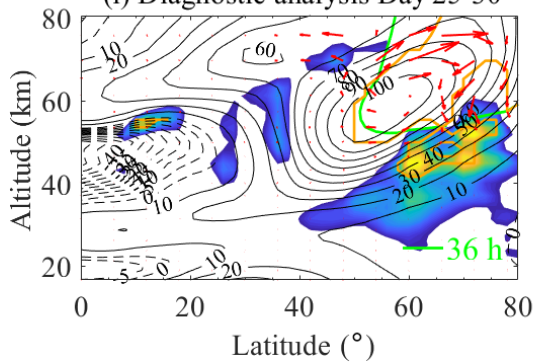

(b) Temp spectrum Day 69-74

K

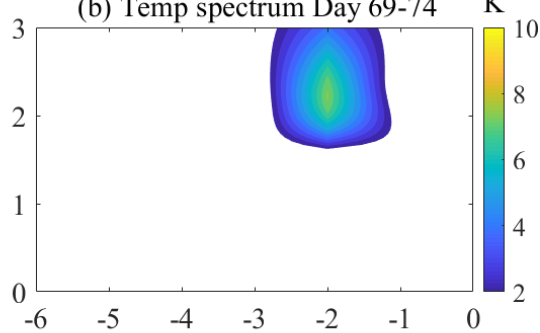

(d) Temp Structure of $53 \mathrm{~h} \quad \mathrm{~K}$
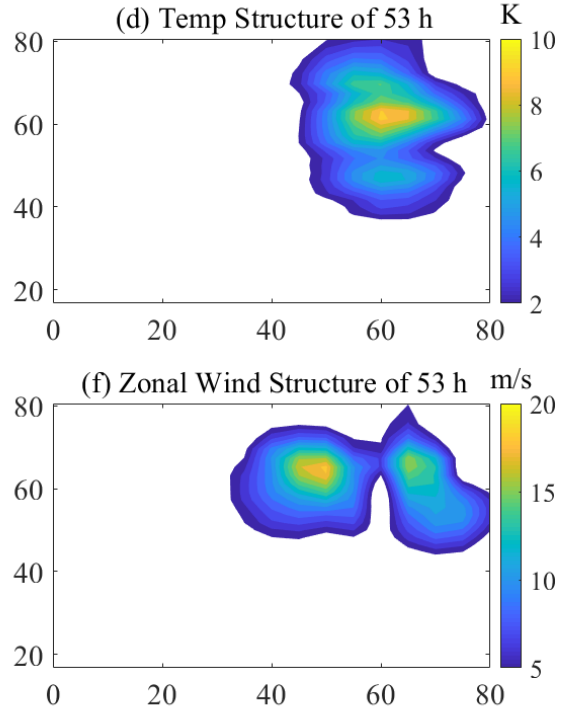

(h) Merid Wind Structure of $53 \mathrm{~h} \mathrm{~m} / \mathrm{s}$
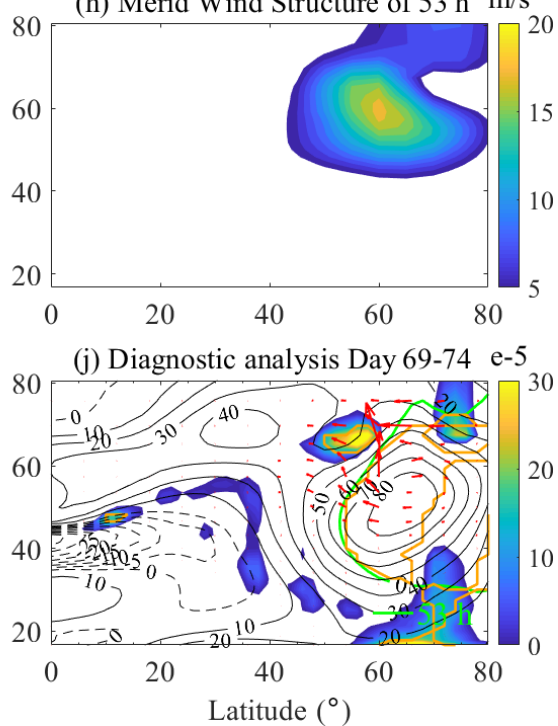

Figure 10. Same as Fig. 9 but for E2 during the 2019 boreal winter period.

at $\sim 50-60^{\circ} \mathrm{N}$ and $\sim 60-70 \mathrm{~km}$ is stronger on days $25-30$ than on days $69-74$, the instability at $\sim 50-60^{\circ} \mathrm{N}$ and $\sim 60$ $70 \mathrm{~km}$ is stronger on days $69-74$ than on days $25-30$. The temperature amplitude results indicate that E2 absorbs sufficient energy to be amplified under the background conditions on days 69-74, with a stronger temperature amplitude on days 69-74 (Fig. 10a, b).
Figure 11a and b show the observed spectra of E3 at $\sim 59.2 \mathrm{~km}$ and $\sim 60-70^{\circ} \mathrm{N}$ on days $35-38$ and $53-56$, and the wave periods of locked wavenumber -3 are $\sim 29$ and $\sim 27 \mathrm{~h}$, respectively. The corresponding temperature spatial structures of these E3 periods (i.e., $\sim 29$ and $\sim 27 \mathrm{~h}$ ) are shown in Fig. 11c and d. The temperature spatial structure of E3 shows an obvious amplitude bimodal structure at $\sim 50$ 
$60^{\circ} \mathrm{N}$ and $\sim 60 \mathrm{~km}$ and $\sim 50-60^{\circ} \mathrm{N}$ and $\sim 70 \mathrm{~km}$, with the maximum at $\sim 50-60^{\circ} \mathrm{N}$ and $\sim 60 \mathrm{~km}$. The strongest temperature amplitude of $\mathrm{E} 3$ occurs at $\sim 60 \mathrm{~km}$ and $\sim 50-60^{\circ} \mathrm{N}$ with an amplitude of $\sim 6 \mathrm{~K}$ on days $35-38$, and the other peak is $\sim 5 \mathrm{~K}\left(\sim 50-60^{\circ} \mathrm{N}\right.$ and $\left.\sim 70 \mathrm{~km}\right)$. The temperature amplitude of $\sim 4 \mathrm{~K}$ occurs at $\sim 60 \mathrm{~km}(\sim 70 \mathrm{~km})$ and $\sim 50-60^{\circ} \mathrm{N}$ during days 53-56. The corresponding spatial structures of zonal wind and meridional wind of these E3 events are illustrated in Fig. 6e-h. The zonal wind spatial structure of E3 shows an obvious amplitude bimodal structure at $\sim 40-50^{\circ} \mathrm{N}$ and $\sim 70 \mathrm{~km}$ and $\sim 60-70^{\circ} \mathrm{N}$ and $\sim 70 \mathrm{~km}$. The zonal wind amplitudes of E3 occur at $\sim 40-50^{\circ} \mathrm{N}$ and $\sim 70 \mathrm{~km}$ with an amplitude of $\sim 15 \mathrm{~m} / \mathrm{s}$ on days 35-38 and $\sim 12 \mathrm{~m} / \mathrm{s}$ at $\sim 60$ $70^{\circ} \mathrm{N}$ and $\sim 70 \mathrm{~km}$. The maximum zonal wind amplitude of E3 appears at $\sim 40-50^{\circ} \mathrm{N}$ and $\sim 70 \mathrm{~km}\left(\sim 60-70^{\circ} \mathrm{N}\right.$ and $\sim 70 \mathrm{~km})$ with an amplitude of $\sim 7 \mathrm{~m} / \mathrm{s}(\sim 6 \mathrm{~m} / \mathrm{s})$ on days 53 56. The amplitude of E3 meridional wind reaches $\sim 22 \mathrm{~m} / \mathrm{s}$ at $\sim 50-60^{\circ} \mathrm{N}$ and $\sim 70 \mathrm{~km}$ (days $35-38$ ) and $\sim 12 \mathrm{~m} / \mathrm{s}$ at $\sim 60-70^{\circ} \mathrm{N}$ and $\sim 70 \mathrm{~km}$ (days $53-56$ ).

Obviously, the instability and appropriate background wind at the mid-latitudes between $\sim 50$ and $\sim 70 \mathrm{~km}$ and the interaction near the critical layers $(\sim 29$ and $\sim 27 \mathrm{~h}$ ) dramatically amplify the propagation of E3 (see Fig. 11i and j). The background wind is similar on days $35-38$ and $53-56$, and the former period is relatively unstable. This finding indicates that E3 in propagation is more likely to gather sufficient energy to be amplified on days 35-38. The instability and appropriate background wind at the middle-high latitudes between $\sim 50$ and $\sim 70 \mathrm{~km}$ drastically amplify the propagation of E3, which is enhanced by the interaction near the critical layers ( $\sim 29$ and $\sim 27 \mathrm{~h}$ ) and the positive-refractive-index region (Fig. 11i, j). In particular, the strong instability and weak background wind at $\sim 50-60^{\circ} \mathrm{N}$ and $\sim 60-70 \mathrm{~km}$ on days 35-38 generate sufficient energy for the propagation and amplification of EP flux into the lower atmosphere and ultimately point toward the Equator at $50 \mathrm{~km}$. The EP flux propagates to the lower atmosphere during days 35-38, and it is amplified by interactions at the critical layer $(\sim 29 \mathrm{~h})$. In addition, weak instability and weak background winds on days $53-56$ at $\sim 50-60^{\circ} \mathrm{N}$ and $\sim 60-70 \mathrm{~km}$ provide the energy to amplify E3 propagation. Combined with Fig. 11c and $\mathrm{d}$, the stronger the instability at $\sim 50-60^{\circ} \mathrm{N}$ and $\sim 60-70 \mathrm{~km}$, the stronger the temperature amplitude of E3. The results show that the instability on days $35-38$ at $\sim 50-60^{\circ} \mathrm{N}$ and $\sim 60-70 \mathrm{~km}$ is the primary reason for the propagation and amplification of EP flux into the lower atmosphere.

\subsection{Comparison between $\mathrm{SH}$ and $\mathrm{NH}$}

The observed latitude and maximum temperature amplitude for eastward planetary waves (i.e., E1, E2, E3, E4) decrease and weaken with increasing zonal wavenumber in the SH, reaching $\sim 70-80, \sim 60-70, \sim 60-70$ and $\sim 50-$ $60^{\circ} \mathrm{S}$ and $\sim 10, \sim 9, \sim 6$ and $\sim 3 \mathrm{~K}$, respectively. In addition, the occurrence date moves earlier with increasing zonal wavenumber. The temperature spatial structure demonstrates a bimodal-peak structure $(\sim 50$ and $\sim 60 \mathrm{~km})$, mainly located at $\sim 50 \mathrm{~km}$. The maximum zonal wind amplitudes of E1 and $\mathrm{E} 2$ and of $\mathrm{E} 3$ and $\mathrm{E} 4$ are almost the same, $\sim 20$ and $\sim 10 \mathrm{~m} / \mathrm{s}$, respectively. The maximum meridional wind amplitudes of $\mathrm{E} 1, \mathrm{E} 2, \mathrm{E} 3$ and $\mathrm{E} 4$ are $\sim 17, \sim 27, \sim 16$ and $\sim 11 \mathrm{~m} / \mathrm{s}$, respectively. The wave period of E1 tends to become shorter from 5 to $3 \mathrm{~d}$, while $\mathrm{E} 2$ and $\mathrm{E} 3$ are close to $\sim 40$ and $\sim 30 \mathrm{~h}$ and E4 remains at $\sim 24 \mathrm{~h}$. E1, E2, E3 and E4 are more favorable to propagation in the SH winter and are abruptly amplified by the mean flow instabilities at the middle latitudes between $\sim 40$ and $\sim 70 \mathrm{~km}$. With the propagation of EP flux into the lower atmosphere, it finally propagates toward the Equator at $\sim 50 \mathrm{~km}$. In addition, the propagation of EP flux for E1 to the upper atmosphere might be influenced by the instability and background wind at the Antarctic at $\sim 50 \mathrm{~km}$.

The observed latitudes of E1 and E2 (E3) decrease with increasing wavenumber in the $\mathrm{NH}$, at $\sim 70-80$ and $\sim 60$ $70^{\circ} \mathrm{N}\left(\sim 60-70^{\circ} \mathrm{N}\right)$. With a bimodal-peak structure located at $\sim 70 \mathrm{~km}$, the temperature spatial structures of E1, E2 and $\mathrm{E} 3$ reach $\sim 10, \sim 9$ and $\sim 6 \mathrm{~K}$, respectively. The maximum zonal wind amplitudes for E1, E2 and E3 occur at $\sim 50$ $80^{\circ} \mathrm{N}$ and $\sim 70 \mathrm{~km}$, and their amplitudes are almost equal to $\sim 18 \mathrm{~m} / \mathrm{s}$. The maximum meridional winds of E1, E2 and E3 occur at $\sim 50-80^{\circ} \mathrm{N}$ and $\sim 70 \mathrm{~km}$ with amplitudes of $\sim 22 \mathrm{~m} / \mathrm{s}, \sim 18 \mathrm{~m} / \mathrm{s}$ and $\sim 22 \mathrm{~m} / \mathrm{s}$, respectively. The wave period of E1 tends to be shorter at 5-3d, and E2 and E3 are close to $\sim 48$ and $\sim 30 \mathrm{~h}$. In addition, E1, E2 and E3 are more favorable to propagation in the $\mathrm{NH}$ winter and are dramatically amplified by the mean flow instabilities at the middle latitudes between $\sim 40$ and $\sim 70 \mathrm{~km}$, with the propagation of EP flux into the lower atmosphere and then toward the Equator at $\sim 50 \mathrm{~km}$.

\section{Summary and conclusions}

Based on the MERRA-2 temperature and wind observations in 2019, we present for the first time an extensive study of the global variation in eastward planetary wave activity, including E1, E2, E3 and E4 in the stratosphere and mesosphere. We presented the analysis results only for the year 2019 due to the representative of the wave activities for the entire range of 2013-2020. The temperature and wind amplitude and wave periods of each event were determined using 2-D least-squares fitting. Our study covered the spatial and temporal patterns of the eastward planetary waves in both hemispheres with a comprehensive diagnostic analysis on their propagation and amplification. The key findings of this study are summarized below.

The latitudes for the maximum (temperature, zonal and meridional wind) amplitudes of E1, E2, E3 and E4 decrease with increasing wavenumber in the $\mathrm{SH}$ and $\mathrm{NH}$. The E1, E2, E3 and E4 events occur earlier with increasing zonal wavenumber in the SH. In addition, eastward wave modes 
(a) Temp spectrum Day 35-38

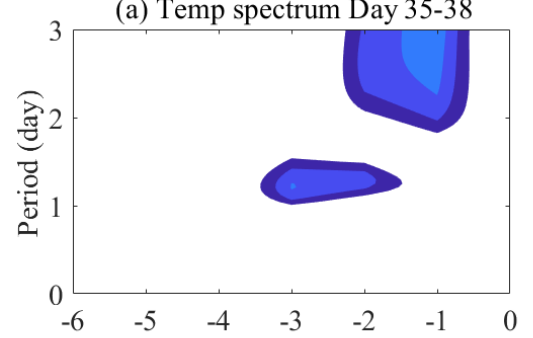

(c) Temp Structure of $29 \mathrm{~h}$

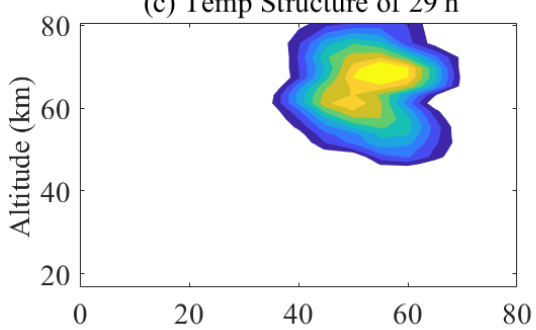

(e) Zonal Wind Structure of $29 \mathrm{~h}$

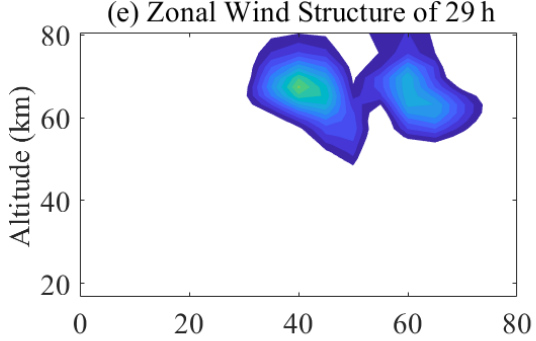

(g) Merid Wind Structure of $29 \mathrm{~h}$

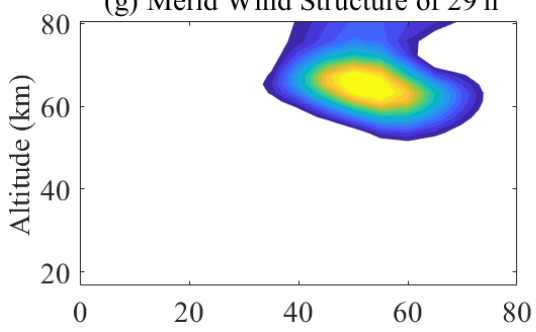

(i) Diagnostic analysis Day 35-38

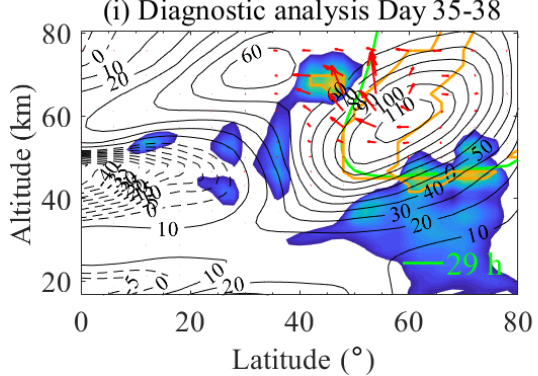

(b) Temp spectrum Day 53-56 K

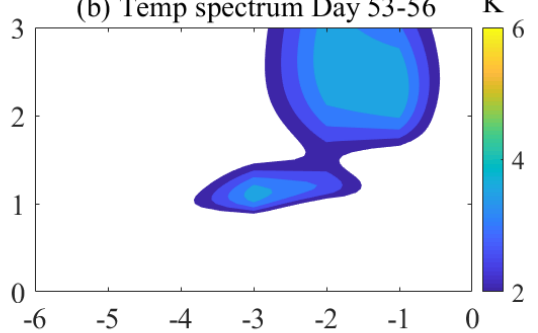

(d) Temp Structure of $27 \mathrm{~h} \quad \mathrm{~K}$
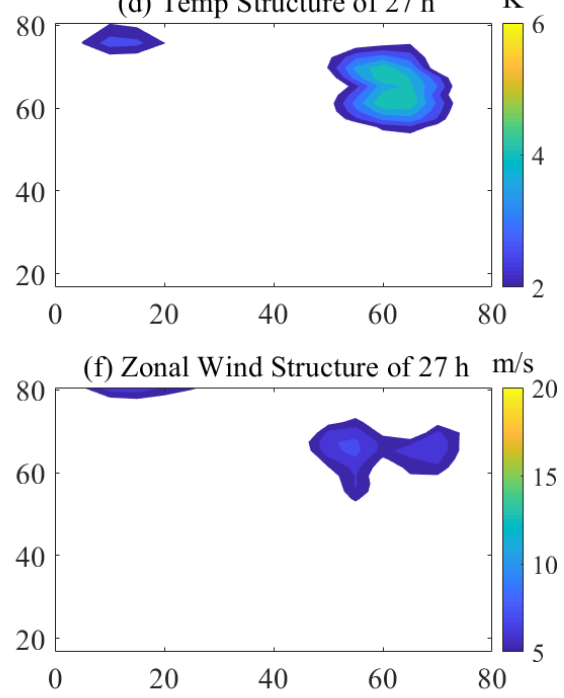

(h) Merid Wind Structure of $27 \mathrm{~h} \mathrm{~m} / \mathrm{s}$
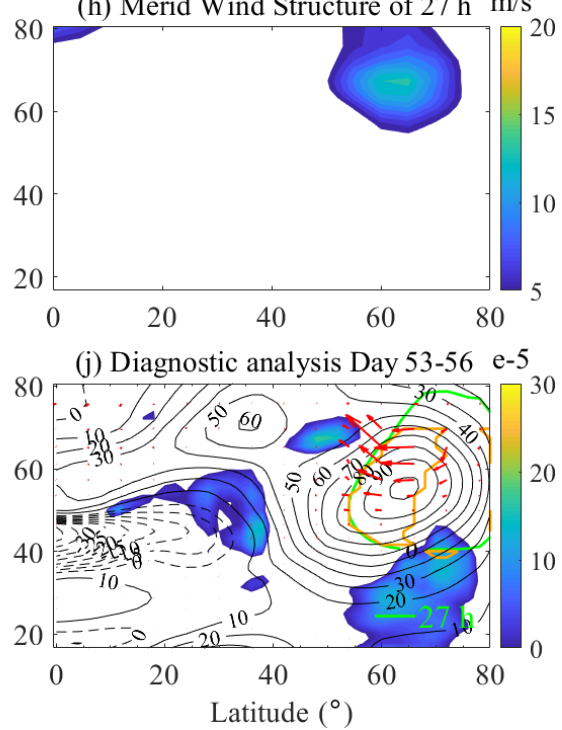

Figure 11. Same as Fig. 9 but for E3 during the 2019 boreal winter period.

exist during summer periods with westward background wind in both hemispheres.

The temperature spatial structures of E1, E2, E3 and E4 present a double-peak structure, which is located at $\sim 50$ and $\sim 60 \mathrm{~km}$ in the $\mathrm{SH}$ and $\sim 60$ and $\sim 70 \mathrm{~km}$ in the NH. Furthermore, the lower peak is usually larger than the higher one.
The maximum (temperature, zonal and meridional wind) amplitudes of E1, E2 and E3 decline with rising zonal wavenumber in the $\mathrm{SH}$ and $\mathrm{NH}$. The maximum temperature amplitudes in the SH are slightly larger and lie lower than those in the NH. In addition, the meridional wind amplitudes are slightly larger than those of the zonal wind in the SH and $\mathrm{NH}$. 
The wave period of the E1 mode ranges between $3-5 \mathrm{~d}$ in both hemispheres, while the period of the E2 mode is slightly longer in the $\mathrm{NH}(\sim 48 \mathrm{~h})$ than in the $\mathrm{SH}(\sim 40 \mathrm{~h})$. The periods of E3 in both $\mathrm{SH}$ and $\mathrm{NH}$ are $\sim 30 \mathrm{~h}$, while the period of $\mathrm{E} 4 \mathrm{is} \sim 24 \mathrm{~h}$.

The eastward planetary wave is more favorable to propagation in the winter hemisphere and is drastically amplified by the mean flow instabilities and appropriate background winds in the polar region and the middle latitudes between $\sim 40$ and $\sim 80 \mathrm{~km}$. Furthermore, the amplification of planetary waves through wave-mean flow interaction occurs easily close to their critical layer. In addition, the direction of EP flux ultimately points toward the Equator.

The strong instability and appropriate background wind in the lower layer of the Antarctic region might generate adequate energy to promote $\mathrm{E} 1$ propagation and amplification to the upper atmosphere.

Overall, this study demonstrated how the background zonal wind in the polar middle atmosphere affects the dynamics of eastward planetary waves in the polar middle atmosphere.

Code availability. Code is available at http://hdl.pid21.cn/21 . 86116.7/04.99.01720 (Liang, 2021).

Data availability. The MERRA-2 data (MERRA2_300.tavg3_ 3d_asm_Nv) can be accessed via http://disc.gsfc.nasa.gov (Bosilovich et al., 2015).

Author contributions. LT carried out the data processing and analysis and wrote the manuscript. SYG and XKD contributed to reviewing the article.

Competing interests. The contact author has declared that neither they nor their co-authors have any competing interests.

Disclaimer. Publisher's note: Copernicus Publications remains neutral with regard to jurisdictional claims in published maps and institutional affiliations.

Acknowledgements. This work was performed in the framework of space physics research (SPR). The authors thank NASA for free online access to the MERRA-2 temperature reanalysis.

Financial support. This research has been supported by the National Natural Science Foundation of China (grant nos. 41704153, 41874181 and 41831071).
Review statement. This paper was edited by Peter Haynes and reviewed by two anonymous referees.

\section{References}

Alexander, S. P. and Shepherd, M. G.: Planetary wave activity in the polar lower stratosphere, Atmos. Chem. Phys., 10, 707-718, https://doi.org/10.5194/acp-10-707-2010, 2010.

Andrews, D., Holton, J., and Leovy, C.: Middle Atmosphere Dynamics, 489 pp., Middle Atmosphere Dynamics, Volume 40 "International Geophysics”, Academic Press, ISBN 978-01-2058576-2, 1987.

Bali, K., Dey, S., Ganguly, D., and Smith, K. R.: Space-time variability of ambient $\mathrm{PM}_{2.5}$ diurnal pattern over India from 18-years (2000-2017) of MERRA-2 reanalysis data, Atmos. Chem. Phys. Discuss. [preprint], https://doi.org/10.5194/acp-2019-731, 2019.

Bosilovich, M. G., Akella, S., Coy, L., Cullather, R., Draper, C., Gelaro, R., Kovach, R., Liu, Q., Molod, A., Norris, P., Wargan, K., Chao, W., Reichle, R., Takacs, L., Vikhliaev, Y., Bloom, S., Collow, A., Firth, S., Labow, G., Partyka, G., Pawson, S., Reale, O., Schubert, S. D., Suarez, M., and Global Modeling and Assimilation Office (GMAO): MERRA-2, Greenbelt, MD, USA, Goddard Earth Sciences Data and Information Services Center (GES DISC) [data set], available at: http://disc.gsfc.nasa.gov (last access: 2 June 2021), 2015.

Coy, L., Štajner, I., DaSilva, A. M., Joiner, J., Rood, R. B., Pawson, S., and Lin, S. J.: High-Frequency Planetary Waves in the Polar Middle Atmosphere as Seen in a Data Assimilation System, J. Atmos. Sci., 60, 2975-2992, https://doi.org/10.1175/15200469(2003)060<2975:Hpwitp>2.0.Co;2, 2003.

Gu, S.-Y., Li, T., Dou, X., Wu, Q., Mlynczak, M. G., and Russell Iii, J. M.: Observations of Quasi-Two-Day wave by TIMED/SABER and TIMED/TIDI, J. Geophys. Res.-Atmos., 118, 1624-1639, https://doi.org/10.1002/jgrd.50191, 2013.

Gu, S.-Y., Liu, H.-L., Pedatella, N. M., Dou, X., and Shu, Z.: The quasi-2 day wave activities during 2007 boreal summer period as revealed by Whole Atmosphere Community Climate Model, J. Geophys. Res.-Space, 121, 7256-7268, https://doi.org/10.1002/2016JA022867, 2016a.

Gu, S.-Y., Liu, H.-L., Pedatella, N. M., Dou, X., Li, T., and Chen, T.: The quasi 2 day wave activities during 2007 austral summer period as revealed by Whole Atmosphere Community Climate Model, J. Geophys. Res.-Space, 121, 2743-2754, https://doi.org/10.1002/2015JA022225, 2016b.

Gu, S.-Y., Liu, H.-L., Pedatella, N. M., Dou, X., and Liu, Y.: On the wave number 2 eastward propagating quasi 2 day wave at middle and high latitudes, J. Geophys. Res.-Space, 122, 44894499, https://doi.org/10.1002/2016JA023353, 2017.

Gu, S.-Y., Liu, H.-L., Dou, X., and Jia, M.: Ionospheric Variability Due to Tides and Quasi-Two Day Wave Interactions, J. Geophys. Res.-Space, 123, 1554-1565, https://doi.org/10.1002/2017JA025105, 2018a.

Gu, S.-Y., Dou, X., Pancheva, D., Yi, W., and Chen, T.: Investigation of the Abnormal Quasi 2-Day Wave Activities During the Sudden Stratospheric Warming Period of January 2006, J. Geophys. Res.-Space, 123, 6031-6041, https://doi.org/10.1029/2018JA025596, 2018b. 
Gu, S.-Y., Ruan, H., Yang, C.-Y., Gan, Q., Dou, X., and Wang, N.: The Morphology of the 6-Day Wave in Both the Neutral Atmosphere and F Region Ionosphere Under Solar Minimum Conditions, J. Geophys. Res.-Space, 123, 4232-4240, https://doi.org/10.1029/2018JA025302, 2018c

Gu, S.-Y., Dou, X.-K., Yang, C.-Y., Jia, M., Huang, K.-M., Huang, C.-M., and Zhang, S.-D.: Climatology and Anomaly of the Quasi-Two-Day Wave Behaviors During 2003-2018 Austral Summer Periods, J. Geophys. Res.-Space, 124, 544-556, https://doi.org/10.1029/2018JA026047, 2019.

Lainer, M., Hocke, K., and Kämpfer, N.: Long-term observation of midlatitude quasi 2-day waves by a water vapor radiometer, Atmos. Chem. Phys., 18, 12061-12074, https://doi.org/10.5194/acp-18-12061-2018, 2018.

Li, H., Pilch Kedzierski, R., and Matthes, K.: On the forcings of the unusual Quasi-Biennial Oscillation structure in February 2016, Atmos. Chem. Phys., 20, 6541-6561, https://doi.org/10.5194/acp-20-6541-2020, 2020.

Liang, T.: Analysis data and code based on the study of Middle East propagating planetary waves in the polar middle atmosphere, available at: http://hdl.pid21.cn/21.86116.7/04.99.01720, last access: 2 June 2021.

Lilienthal, F. and Jacobi, Ch.: Meteor radar quasi 2-day wave observations over 10 years at Collm $\left(51.3^{\circ} \mathrm{N}, 13.0^{\circ} \mathrm{E}\right)$, Atmos. Chem. Phys., 15, 9917-9927, https://doi.org/10.5194/acp15-9917-2015, 2015.

Limpasuvan, V. and Wu, D. L.: Anomalous two-day wave behavior during the 2006 austral summer, Geophys. Res. Lett., 36, L04807, https://doi.org/10.1029/2008GL036387, 2009.

Liu, G., England, S. L., and Janches, D.: Quasi Two-, Three-, and Six-Day Planetary-Scale Wave Oscillations in the Upper Atmosphere Observed by TIMED/SABER Over $\sim 17$ Years During 2002-2018, J. Geophys. Res.-Space, 124, 9462-9474, https://doi.org/10.1029/2019JA026918, 2019.

Liu, H. L., Talaat, E. R., Roble, R. G., Lieberman, R. S., Riggin, D. M., and Yee, J. H.: The 6.5-day wave and its seasonal variability in the middle and upper atmosphere, J. Geophys. Res.-Atmos., 109, D21112, https://doi.org/10.1029/2004JD004795, 2004.

Lu, X., Chu, X., Fuller-Rowell, T., Chang, L., Fong, W., and Yu, Z.: Eastward propagating planetary waves with periods of 1-5 days in the winter Antarctic stratosphere as revealed by MERRA and lidar, J. Geophys. Res.-Atmos., 118, 9565-9578, https://doi.org/10.1002/jgrd.50717, 2013.

Manney, G. L. and Randel, W. J.: Instability at the Winter Stratopause: A Mechanism for the 4-Day Wave, J. Atmos. Sci., 50, 3928-3938, https://doi.org/10.1175/15200469(1993)050<3928:IATWSA>2.0.CO;2, 1993.

Matthias, V. and Ern, M.: On the origin of the mesospheric quasi-stationary planetary waves in the unusual Arctic winter 2015/2016, Atmos. Chem. Phys., 18, 4803-4815, https://doi.org/10.5194/acp-18-4803-2018, 2018.

Meek, C. E., Manson, A. H., Franke, S. J., Singer, W., Hoffmann, P., Clark, R. R., Tsuda, T., Nakamura, T., Tsutsumi, M., Hagan, M., Fritts, D. C., Isler, J., and Portnyagin, Y. I.: Global study of northern hemisphere quasi-2-day wave events in recent summers near $90 \mathrm{~km}$ altitude, J. Atmos. Terr. Phys., 58, 1401-1411, https://doi.org/10.1016/0021-9169(95)00120-4, 1996.

Merzlyakov, E. G. and Pancheva, D. V.: The 1.5-5-day eastward waves in the upper stratosphere-mesosphere as observed by the Esrange meteor radar and the SABER instrument, J. Atmos. Sol.-Terr. Phys., 69, 2102-2117, https://doi.org/10.1016/j.jastp.2007.07.002, 2007.

Molod, A., Takacs, L., Suarez, M., Bacmeister, J., Song, I. S., and Eichmann, A.: The GEOS-5 Atmospheric General Circulation Model: Mean Climate and Development from MERRA to Fortuna, Technical Report Series on Global Modeling and Data Assimilation, Volume 28, Goddard Space Flight Center Greenbelt, Maryland, NASA, 2012.

Molod, A., Takacs, L., Suarez, M., and Bacmeister, J.: Development of the GEOS-5 atmospheric general circulation model: evolution from MERRA to MERRA2, Geosci. Model Dev., 8, 1339-1356, https://doi.org/10.5194/gmd-8-1339-2015, 2015.

Palo, S. E., Roble, R. G., and Hagan, M. E.: Middle atmosphere effects of the quasi-two-day wave determined from a General Circulation Model, Earth Planet. Space, 51, 629-647, https://doi.org/10.1186/BF03353221, 1999.

Palo, S. E., Forbes, J. M., Zhang, X., Russell Iii, J. M., and Mlynczak, M. G.: An eastward propagating two-day wave: Evidence for nonlinear planetary wave and tidal coupling in the mesosphere and lower thermosphere, Geophys. Res. Lett., 34, L07807, https://doi.org/10.1029/2006GL027728, 2007.

Pancheva, D., Mukhtarov, P., Siskind, D. E., and Smith, A. K.: Global distribution and variability of quasi 2 day waves based on the NOGAPS-ALPHA reanalysis model, J. Geophys. Res.-Space, 121, 11422-11449, https://doi.org/10.1002/2016JA023381, 2016.

Rao, N. V., Ratnam, M. V., Vedavathi, C., Tsuda, T., Murthy, B. V. K., Sathishkumar, S., Gurubaran, S., Kumar, K. K., Subrahmanyam, K. V., and Rao, S. V. B.: Seasonal, inter-annual and solar cycle variability of the quasi two day wave in the low-latitude mesosphere and lower thermosphere, J. Atmos. Sol.-Terr. Phy., 152-153, 20-29, https://doi.org/10.1016/j.jastp.2016.11.005, 2017.

Salby, M. L.: The 2-day wave in the middle atmosphere: Observations and theory, J. Geophys. Res.-Oceans, 86, 9654-9660, https://doi.org/10.1029/JC086iC10p09654, 1981.

Sandford, D. J., Schwartz, M. J., and Mitchell, N. J.: The wintertime two-day wave in the polar stratosphere, mesosphere and lower thermosphere, Atmos. Chem. Phys., 8, 749-755, https://doi.org/10.5194/acp-8-749-2008, 2008.

Stray, N. H., Orsolini, Y. J., Espy, P. J., Limpasuvan, V., and Hibbins, R. E.: Observations of planetary waves in the mesospherelower thermosphere during stratospheric warming events, Atmos. Chem. Phys., 15, 4997-5005, https://doi.org/10.5194/acp15-4997-2015, 2015.

Sun, J., Veefkind, J. P., van Velthoven, P., Tilstra, L. G., Chimot, J., Nanda, S., and Levelt, P. F.: Defining aerosol layer height for UVAI interpretation using aerosol vertical distributions characterized by MERRA-2, Atmos. Chem. Phys. Discuss. [preprint], https://doi.org/10.5194/acp-2020-39, 2020.

Tunbridge, V. M., Sandford, D. J., and Mitchell, N. J.: Zonal wave numbers of the summertime 2 day planetary wave observed in the mesosphere by EOS Aura Microwave Limb Sounder, J. Geophys. Res.-Atmos., 116, D11103, https://doi.org/10.1029/2010JD014567, 2011.

Ukhov, A., Mostamandi, S., da Silva, A., Flemming, J., Alshehri, Y., Shevchenko, I., and Stenchikov, G.: Assessment of natural and anthropogenic aerosol air pollution in the Mid- 
dle East using MERRA-2, CAMS data assimilation products, and high-resolution WRF-Chem model simulations, Atmos. Chem. Phys., 20, 9281-9310, https://doi.org/10.5194/acp-209281-2020, 2020.

Venne, D. E. and Stanford, J. L.: Observation of a 4Day Temperature Wave in the Polar Winter Stratosphere, J. Atmos. Sci., 36, 2016-2019, https://doi.org/10.1175/15200469(1979)036<2016:Ooatwi>2.0.Co;2, 1979.

Wang, J. C., Chang, L. C., Yue, J., Wang, W., and Siskind, D. E.: The quasi 2 day wave response in TIME-GCM nudged with NOGAPS-ALPHA, J. Geophys. Res.-Space, 122, 5709-5732, https://doi.org/10.1002/2016JA023745, 2017.

Wu, W.-S., Purser, R. J., and Parrish, D. F.: ThreeDimensional Variational Analysis with Spatially Inhomogeneous Covariances, Mon. Weather Rev., 130, 2905-2916, https://doi.org/10.1175/15200493(2002)130<2905:TDVAWS>2.0.CO;2, 2002.
Xiong, J., Wan, W., Ding, F., Liu, L., Hu, L., and Yan, C.: Two Day Wave Traveling Westward With Wave Number 1 During the Sudden Stratospheric Warming in January 2017, J. Geophys. Res.Space, 123, 3005-3013, https://doi.org/10.1002/2017JA025171, 2018.

Yadav, S., Vineeth, C., Kumar, K. K., Choudhary, R. K., Pant, T. K., and Sunda, S.: Role of the phase of Quasi-Biennial Oscillation in modulating the influence of SSW on Equatorial Ionosphere, 2019 URSI Asia-Pacific Radio Science Conference (AP-RASC), 9-15 March 2019, 1-4, https://doi.org/10.23919/URSIAPRASC.2019.8738274, 2019.

Yamazaki, K., Nakamura, T., Ukita, J., and Hoshi, K.: A tropospheric pathway of the stratospheric quasi-biennial oscillation (QBO) impact on the boreal winter polar vortex, Atmos. Chem. Phys., 20, 5111-5127, https://doi.org/10.5194/acp-205111-2020, 2020. 